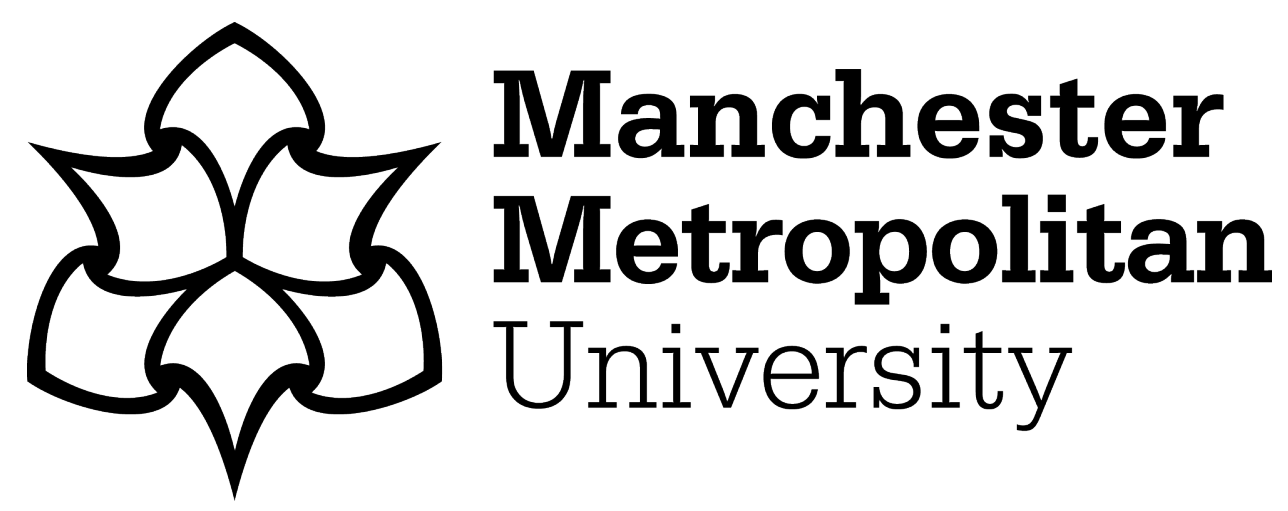

Giovanis, Eleftherios ORCID logoORCID: https://orcid.org/0000-0002-74927461 (2019) Do the Flexible Employment Arrangements Increase Job Satisfaction and Employee Loyalty? Evidence From Bayesian Networks and Instrumental Variables. International Journal of Computational Economics and Econometrics, 9 (1/2). pp. 84-115. ISSN 1757-1170

Downloaded from: https://e-space.mmu.ac.uk/622000/

Version: Accepted Version

Publisher: Inderscience

DOI: https://doi.org/10.1504/IJCEE.2019.097795

Please cite the published version 
Do the Flexible Employment Arrangements Increase Job Satisfaction and Employee Loyalty? Evidence from Bayesian Networks and Instrumental Variables

\section{Eleftherios Giovanis}

1. Adnan Menderes University, Nazilli Faculty of Economics and Administrative Sciences, Cumhuriyet, 09800 İsabeyli, Nazilli, Turkey

2. University of Verona, Department of Economics, Via Cantarane 24, 37129, Italy

Email: giovanis95@gmail.com and eleftherios.giovanis@univr.it 


\title{
Do the Flexible Employment Arrangements Increase Job Satisfaction and Employee Loyalty? Evidence from Bayesian Networks and Instrumental Variables
}

\begin{abstract}
This study explores the relationship between job satisfaction, employee loyalty and two types of flexible employment arrangements; teleworking and flexible timing. The analysis relies on data derived by the Workplace Employee Relations Survey (WERS) in 2004 and 2011. We apply the propensity score matching approach and least squares regressions. Furthermore, we employ the Bayesian Networks (BN) and Directed Acyclic Graphs (DAGs) to confirm the causality between employment types explored and the outcomes of interest. Additionally, we propose an instrumental variables (IV) approach based on the BN framework. The results support that a positive causal effect from these employment arrangements on job satisfaction and employee loyalty is present.
\end{abstract}

Keywords: Bayesian Networks; Directed Acyclic Graphs; Employee Loyalty; Employment Arrangements; Flexible Timing; Job Satisfaction; Teleworking; Workplace Employment Relations Survey. 


\section{Introduction}

Work especially the last years with the fast enhancement of technology and networks has been disconnected from a particular place and time and information technologies have made it possible (Golden et al., 2006). While the traditional place of work used to be the employer's premises, nowadays it is carried out in other locations, such as the employee's home, client's premises, other locations or while traveling. Advances in technology reshape the relationship between work and home, where in some cases the traditional flow of employees from home to office is reversed (Bailyn, 1988). The virtualisation and this shock of the contemporary organisation has been evolved as a vital necessity for the firms to be able to compete for workers globally and advances in information technology provide the means (WorldatWork, 2011). By 2016 it is estimated that around 90 million of self-employed and employed U.S. workers will work from home or from a remote location at least 2 to 3 days a week (Lister and Harnish, 2011). This study examines the relationship of teleworking or home-based working and flexible timing with job satisfaction and the employee loyalty in a sample of firms in Great Britain using the Workplace Employee Relations Survey (WERS) in 2004 and 2011.

Teleworking is a term used to describe an alternative work arrangement that enables employees to work from anywhere other than the traditional work setting or employer's premises. Teleworking or telecommuting, as it's sometimes called, has gained increasing popularity and acceptance throughout the United States and the world (Gajendran and Harrison, 2007). According to the study by Crandall and Gao (2005), teleworking has become an international phenomenon. Thus, teleworkers spend some portion of their time away from the conventional workplace, working from home, and communicate by means of computer-based technology (Niles, 1994). Previous studies have outlined the reasons for the growth of 
teleworking and other kinds of flexible employment types, which are owned mainly to their perceived benefits. In particular, these benefits refer on both teleworker and employer including job satisfaction, increasing productivity, organisational loyalty, improved employee morale and employer retention and cost savings in space office among others (Bélanger, 1999; Potter, 2003). Second, we examine the relationship between teleworking and job satisfaction, as well as, the relationship between teleworking and employee loyalty. The above-mentioned linkages are explored using Ordinary Least Squares (OLS) and Ordered Probit models based on propensity score matching, accounting for selection and heterogeneous bias. In addition, this study extends the previous literature, proposing a Bayesian Network framework and Directed Acyclic Graphs (DAGs) representation to examine and confirm the causal effect of flexible working employment arrangements on job satisfaction and employee's loyalty. The main aim of using BN and IV approaches is the plausible degree of reverse causality between job satisfaction and the flexible employment arrangements explored in this study. More specifically, while these flexible employment schemes may affect the job satisfaction, the less satisfied employees may search workplaces that offer those schemes. The findings support a positive effect from the employment arrangements examined on both job satisfaction and employee loyalty. This can have possible policy implications, not only to employees and firms, but to society overall, which we discuss in the last part. We should notice that there are additional flexible employment types, including the changing shifts, the option of switching from part-time to full time and vice versa, and the compressed hours, indicating that the employee has the option to work the same weekly hours in 4 days instead of 5 . However, the purpose of the paper is not to follow an extensive analysis of all the possible flexible employment types, but to confirm whether there is a causal effect from the employment types to job satisfaction and employee's loyalty. Furthermore, as we mentioned 
earlier, out aim is to present an alternative approach to investigate whether and which instrument can be used based on DAGs and BN framework, which can be otherwise difficult to be found. The findings derived from the IV using the BN framework are very close with those found by the traditional IV approach.

The paper is organised as follows: Section 2 is devoted to the literature review on teleworking, job satisfaction and performance. Section 3 presents the methodology and the data used in the study. Section 4 considers the results and section 5 presents the concluding remarks and areas for future research.

\section{Literature Review}

In this section we briefly discuss previous research studies on the association between teleworking and job satisfaction. Organisation theorists have long recognised that any kind of interaction on the working environment can be an important determinant of job satisfaction. Sims et al. (1976) suggest that jobs, offering opportunities feedback, friendship and interaction with other people can improve employee's job satisfaction. Earlier studies note that face-to-face interaction is associated with positive outcomes (Olson et al., 2002). Social interaction at work can facilitate social presence, foster mutuality and common ground and improve communication quality (Short et al., 1976; Burgoon et al., 2002). Employees who face a small social presence at work and increased reliance on technology based job activities may experience lower levels of proper communication and less communication richness and quality Lowry et al., 2006). On the other hand, recent research studies confirm a positive relationship between teleworking and job satisfaction (Gajendran and Harrison, 2007), while other studies have found a curvilinear 
association, where increases of the teleworking hours increase the employee's job satisfaction up to a point, after which the effects slightly fade out (Golden and Veiga, 2015). Thus, the traditionally belief that the face-to-face interactions at work have positive effects on job satisfaction may be overestimated and over-generalised. Fonner and Roloff (2010) using a sample of 89 teleworkers and 103 office-based employees applied a path analysis to test the adequacy of their mediation model and to examine the relationship between teleworking and job satisfaction. Additionally, they examined the indirect paths from teleworking to job satisfaction through work-life conflict, information stress exchange frequency and quality, stress from meetings and interruptions and general politics. Their results support that teleworking directly affects job satisfaction positively.

Previous studies explored the effects of precarious-compressed employment schemes for casual workers (Velayutham, 2013; Wilson and Ebert, 2013). The studies found that casual workers report less flexible experience when it comes to daily working routines and are more likely to report more instances of distress and social instability that can be traced back to job insecurity. However, this study explores two flexible employment schemes for permanent staff and not for casual workers. The difference is that amongst the firms explored, the employees have the option to choose the flexible working schedules examined. Since the casual relationship between the job satisfaction and the flexible employment schemes examined in this study is still unknown on a large scale study, this paper aims to examine the relationship between teleworking, job satisfaction and turnover intentions or employee loyalty. 


\section{Materials and Methods}

\subsection{Theoretical Framework}

In this section we discuss three main topics. First, we describe the main flexible employment schemes examined in this study, and their possible relationship with the main outcomes of interest; job satisfaction and employee loyalty. Second, we will present our instrumental variables following earlier studies, and how their legitimacy can be supported by the Bayesian Networks and the empirical results followed in the next sections. Third, we present the control variables used in the regression analysis described in the next section and their possible role on job satisfaction and employee loyalty.

3.1.1 Relationship between Flexible Employment Schemes, Job Satisfaction and Employee Loyalty

As we mentioned, we examine two flexible employment schemes; flexi-time (schedule) and home teleworking (location). Regarding the former, the working schedule is set up and based on the employees' needs and within set up parameters approved by a supervisor. This employment scheme may take various forms, such as a worker must work 40 hours per week and be present in the workplace, but s/he can define new standard working hours, to adjust the arrival and departure times on a daily basis, or occasionally to work extra hours one day and to make up shorter hours worked on another day. The second scheme is teleworking, and while this may take various forms, including work at home, work at client's premises, or other location that minimises disruptions, in this study we explore only the home teleworkers. In this environment, employees work remotely from their homes, usually using information and communication 
technology (ICT) tools. Case examples include employees who telework from home on Monday and Friday and at the office the rest days of the week, and technicians and craft workers may bring materials from their workplace-firm and work at home 2 days per week. Other example includes the clerical workers and policy researchers, who may occasionally work at home to avoid possible disruptions, especially when a demanded analysis and complicated lengthy report with strict deadlines is required to be completed. Overall, employees implementing flexible working schedules, and especially teleworkers, may encounter fewer distractions than the officebased employees, where workplaces characterised by disruptions and interruptions generate stress about employees' ability to produce the required outcome and reduce job satisfaction (Makin et al., 1988; Mann et al., 2000; Luong and Rogelberg, 2005).

Shockley and Allen (2012) discuss two main motivation-theories that companies offer flexible employment opportunities and the reasons the employees are likely to implement them. The first is life-management motives and the second is the work-related motives. Originally, flexible employment was created as tool to allow employees to facilitate, cope and manage multiple life roles, such as, childcare, caring of disabled family members, household chores and family obligations, and employees are motivated by life management motives to use flexible employment types (Christensen and Staines, 1990; Galinsky, et al., 1996; Frone and Yardley, 1996; McDonald et al., 2005; Estes, 2005). Therefore, life-management motives help employees to manage both work and personal life.

The second category includes the work-related motives, where the flexible employment arrangements apply to increase one's productivity. Typical examples include cases where employees find it difficult to complete the required work in the office, because of disruptions, many social encounters with other co-workers and nearby conversations (Speier et al., 1999). For 
this reason, some employees may prefer to choose flexible employment schemes, and especially home teleworking. The latter also may optimise the employee's working environment, such as those who prefer listening music or work in silence. This can have a positive effect on job satisfaction and therefore, on productivity. Earlier studies support that productivity is a motivating factor of implementing these employment schemes, but also meta-analysis of quasiexperiments suggests that flexible employment interventions lead to greater productivity and affect positively the supervisor ratings of performance (Baltes et al., 1999; Sharpe et al., 2002; Gajendran and Harrison, 2007).

The second theoretical framework that is related to this study is the boundary theory and the work-family balance. Following this particular theory, flexible employment schedules are interventions that allow the employees to enhance their perceptions about work control, to manage how the work is done, and offer tangible and psychological resource to improve their well-being and increase their job satisfaction (Karasek and Theorell, 1990; Lambert, 2000; Kossek et al., 2006; Gronlund, 2007; Kelly and Moen, 2007). These studies found that employees, who implement the flexible employment schemes examined in this study, exhibit higher levels of loyalty, job satisfaction and productivity. Overall, following earlier theories and empirical applications, flexible employment schemes may have a significant impact on job satisfaction and employee loyalty. This effect takes place through two channels. First, through the establishment of family-work balance that improves well-being and results to increase of job satisfaction and second through the control over work can enhance job satisfaction and loyalty. 


\subsubsection{Instrumental Variables}

Next we discuss the choice of instrumental variables for the flexible employment schemes. Following earlier studies we instrument flexi-time with computer use percentage in the workplace and whether the employee has dependent children 0-2 years old (Garen, 1988; Scheffel, 2011). People with young kids may particularly demand flexi-time for child caring reasons and this variable should be independent of the error of job satisfaction and employee loyalty equation. Garen (1988) adapted an IV approach correcting for endogeneity and used the non-labour income, house value and dependent children as instruments. While we have no information on the former two variables, we make use of the last one. The other variable that we employ as instrument for both flexible employment types we explore; teleworking and flexitime, is the computer use percentage at workplace. A very limited number of earlier studies used similar instruments, including whether the respondents use internet and computer at home, the frequency of internet use and the computer use at workplace (Jiang, 2008; Zhu and Mason, 2014). The main aim of those studies is the exploration of teleworking impact on vehicle miles travelled (VMT) and commute length, but there is no study so far exploring the impact of teleworking using these instruments. It is commonly supported that these instruments cannot affect directly the job satisfaction, employee loyalty and other outcomes, including miles travelled and commute mode, but only indirectly through the choice to telework.

As a first rough evidence of the instruments employed in the study, we illustrate their relationship with the flexible employment schemes in figures 1-3. More specifically, in figure 1 we present the proportion of home teleworking employees by computer intensity, and we observe that the proportion of home teleworkers is more than 20 per cent in firms that make use of computer more than 50 per cent in the total personnel and only 7 per cent in workplaces with 
computer use intensity equal or less than 50 per cent. In figure 2 we present the same instrument considering the flexi-time, and the respective values are 44 and 32 per cent. In figure 3 we show the proportion of flexi-time employees and we observe that the 48 per cent of the flexi-time employees have a dependent child 0-2 years old.

However, as we discuss in more details in this section and we present the $\mathrm{BN}$ framework in the next part of the study, it is important to include a set of all the available relevant variables that may have a confounding effect and then to conclude which ones should be considered for the $\mathrm{BN}$ and DAG analysis. Implementing DAG we are able to consider only those variables necessary to identify the impact of flexible employment schemes on the outcomes of interest avoiding the selection, confounding and over-control bias as we discuss in more details in the next sections. Additionally, DAG illustrates graphically which variable can be used as an instrument, following also the theoretical framework and empirical applications of the studies we mentioned earlier.

\section{(Insert Figures 1-3)}

\subsubsection{Other Covariates}

In this section we discuss the covariates included in the regression analysis and are categorised to employee and firm characteristics. Regarding the former category we consider gender, age, marital status, education level, wage, trade union membership, how the skills match with the job position and requirement and whether the employee supervise other employees.

Gender differences can be common in the workplace as women may present different expectations than men. Furthermore, women who are secondary bread-winner they may find it easier to leave the labour market, and thus those who are satisfied are more likely to participate 
in the labour market compared to their dissatisfied counterparts (Clark et al., 1996; Gazioglu and Tansel, 2006). Furthermore, controlling for gender is important because can be a confounder also of flexible working schedules, as for instance women may prefer to telework if they have family obligations and children to care of.

Another important confounder is age, which can present a non-monotonic relationship and specifically a U-shaped curve (Clark, 1996; Clark et al., 1996; Gazioglu and Tansel, 2006). Additionally, age can be related with the propensity of choosing flexible working schedules for various reasons. Older workers are more likely to have more experience and work in higher managing positions that allows them to work at home or change the starting and ending working schedules. Also, older employees are more likely to have a dependent child compared to the young workers 18-25 years old.

The next factors of job satisfaction we consider are the education level and the employee's skills matching to job requirements. These are important determinants and have been employed in the empirical work of earlier studies. Education can have a negative effect on job satisfaction, implying that higher educated employees report lower job satisfaction levels. This can be explained by different expectations among the education levels. In particular, if the educated people have more expectations that do not coincide with the skills matched to their job and their outcomes in the labour market are more likely to present lower levels of job satisfaction (Clark, 1996; Clark et al., 1996; Gazioglu and Tansel, 2006). In line with the previous covariates discussed so far, marital status can be a significant factor of job satisfaction and loyalty, but also a determinant to selection of flexible working schedules, as married people are more likely to have dependent children and therefore more inclined to telework or to change the daily working schedules. 
About the firm characteristics we consider the performance related payments, performance appraisal, quality of employee-management relations, the market area, number of workplaceestablishments and the type of the firm. The performance appraisal, performance related payments and the quality and employee-management relations are important factors of job satisfaction and employee loyalty. These are main characteristics of the supervision and task allocation within a workplace that define the organisational structure and which can be very important for the employees' well-being and loyalty and thus for firm's success. Performance appraisal refers to the opportunity for the employees to reflect their performance with their manager and identify their accomplishments in the workplace. Feedback can be important for the employees, as it can drive them and become a motivation for their productivity enhancement. Similarly, firms that provide performance related payments may affect the employees' job satisfaction and increase their loyalty to the firm.

The remained firm characteristics refer to market area, the workplace status, the competition, the number of establishments and the industry. The market area refers on the workplace's activities and whether these activities are limited in local places or are expanded in regional, national and international areas. The competition is a discrete variable that measures whether the workplace faces little or more competition from abroad, while the number of establishments is a categorical variables which shows if there are many workplaces of the same firm, only one or it is a single foreign company, but located in UK. The workplace status indicates the ownership of the workplace, such as public, private, government-owned limited and others, while the industry is measured by dummy variables indicating the four digit standard industrial classification, including fishing, agriculture, mining, manufacturing among others. 


\subsection{The Estimated Model}

The following job satisfaction function for individual $i$, in firm $k$, area-region $j$ at time $t$.

$$
J S_{i, j, k, t}=a_{0}+a_{1} F W A_{i, j, k . t}+\alpha^{\prime} Z_{i, j, k, t}+\theta_{t}+l_{j}+d_{k}+l_{j} T+\varepsilon_{i, j, k, t}
$$

$J S_{i, j, k, t}$ denotes the job satisfaction and $F W A_{i, j, k, t}$ is a dummy indicating whether the respondent is involved in the current type of flexible working arrangement in firm $k$, in region $j$ and in time t. Vector $\mathbf{Z}$ includes individual and firm characteristics, we discussed in the methodology section. The regression controls for standard travel to work areas (TTWA). Set $l_{j}$ is the area fixed effects, which is expressed by the TTWA, $\theta_{t}$ is a time-specific vector, $d_{k}$ is the firm-workplace fixed effects, while $l_{j} T$ is a set of the area-specific linear time trends which controls for

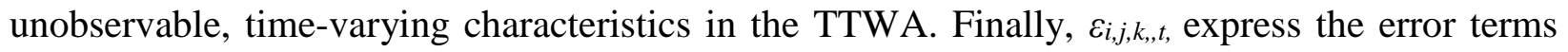
which it is assumed to be iid. The job satisfaction function (1) is estimated using the WERS which was conducted in 2004 and 2011 and has information about employee, employer and firm characteristics. The reason taking only the 2004 and 2011 surveys, instead of previous ones, is that the same sample of workplaces have been collected in those years.

The working arrangements explored in this study are the following: flexi time which means that there is no fixed or specific start and end of the job and the second employment type refers to employees who are home-based workers or teleworkers and work some days of the week at home. Then relation (1) is estimated by replacing the dependent variable with the ordered variable "employee" loyalty and it is estimated with OLS and ordered Probit. We should notice that the propensity score matching (Rosenbaum and Rubin, 1983) has been applied using various algorithms, including the kernel, nearest neighbour and Mahalanobis algorithms, however the results remain the same. The final estimates are based on Mahalanobis algorithm. Additionally, the discrete ordered Probit and Logit models are suggested when the dependent variable is 
ordinal. Nevertheless, we estimate the regressions using both OLS and ordered Probit and the results remain very similar. Earlier studies also found that there are not substantial differences in the estimated results between the two methods (see for more details Ferrer-i-Carbonell and van Praag, 2004; Ferrer-i-Carbonell and Frijters, 2004; Luechinger et al., 2010). We find that the magnitude of the estimated coefficients in ordered Probit regressions are higher, which is always the case, but the marginal effects remain very similar.

\subsection{Bayesian Networks and Instrumental Variables}

In this section the Bayesian Networks (BNs) framework using instrumental variables is described. Probabilistic models based on directed acyclic graphs (DAGs) have a long and rich tradition, which began with the geneticist Sewall Wright (1921a, 1921b, 1921c). The Bayesian Networks have been motivated and developed based on the conditional probability and they rely on Bayes' theorem of probability theory to propagate information between nodes.

A $\mathrm{BN}$ is a graphical structural model that encodes probabilistic relationships among the variables of interest (Heckerman, 1997) ${ }^{1}$. A graph $G(V, E)$ can be referred to as a directed acyclic graph (DAG), when the edges $E$ linking nodes-set of variables $V$ are directed and acyclic. Directed means that edges $E$ represent direct causal effects, while acyclic means that the directed edges do not form circles (Spirtes et al., 2000; Pearl, 2000, 2009). Following Heckerman's (1997) notation, a generic graph is presented in Figure 4. The arrow between $T$ and $F$ in figure 4 means that $T$ may have a direct causal effect on $F$. Similarly, for the arrow between $B$ and $T$ or $A$ and $C$ or $B$ and $C$. In the case where there are missing arrows, it is implied that the strong

\footnotetext{
${ }^{1}$ Major advances have been made in inferring causal relationships from observational data (Pearl, 1988, Spirtes et al., 2000)
} 
assumption of no direct causal effect between two variables is rejected, which is so-called "strong null" hypothesis of no effect. All variables directly or indirectly caused by a given variable are called its descendants. The descendants of $T$ are $F$ and $Y$, while the descendants of $B$ are $C, D, T$ (B's children), $E$ (D's and T's child), $F$ (T's child) and $Y$ (child of $A, C, D, E, F$ ) and similarly for the remained nodes-variables. On the other hand, parents are the variables that direct cause another variable. In figure 4 the only parent of $F$ is $T$, while the only parent of $T$ is $B$. A similar definition to descendants, working on the opposite way, is the variables that directly and indirectly cause of another variable and are called ancestors. For example the ancestors of $F$ are $T$ and $B$, while the ancestors of $E$ are $B, D$, and $T$. Paths are sequences of adjacent arrows that traverse any given variable at most once. The arrows along a path may point in any direction. For example if $B$ is the treatment and $F$ is the outcome then $B \rightarrow T \rightarrow F$ is the only causal path.

\section{(Insert Figure 4)}

The DAG defines a factorisation of the joint probability distribution of $\mathrm{V}=\left\{X_{1}, \ldots, X_{N}\right\}$, often called the global probability distribution, into a set of local probability distributions, one for each variable. The form of the factorisation is given by the Markov property of Bayesian networks which states that every random variable $\mathrm{X}_{\mathrm{i}}$ directly depends only on its parents:

$p(x)=\prod_{i=1}^{m} p\left(x_{i} \mid \operatorname{par}_{i}\right)$

Applying the chain rule of probability, we have:

$$
p(x)=\prod_{i=1}^{m} p\left(x_{i} \mid x_{1}, \ldots ., x_{i-1}\right)
$$


The causal Markov assumption is that each node is independent of its non-descendants in the graph conditional on its parents in the graph. The independence assumptions discussed above and are represented by the graph imply that parameters need to be estimated because the probability distribution for each variable depends only on the node's parents as it is shown in relations (2)-(3) Using the factorisation equation (3) it allows the network factorisation in such a way that it considers each node and its parents in isolation from the rest of the model variables. Otherwise, without employing this factorisation, far more parameters would be required to be estimated and therefore to specify the causal-effect relationships by a fully connected network and "unfactorable" model. Thus, employing the factorisation model (3), the very complex models can be estimated avoiding the combinatorial explosion problem. In Figure 4 the Markov condition for $F$ to $B$ entails the following conditional independence relation:

$$
F \perp B \mid T
$$

More specifically, (4) implies that nodes $F$ and $B$ are independent given $T$ as there is no direct edge connecting them. A similar interpretation can be derived for the remained nodes. In appendix some examples of DAGs, as well as the importance of the factorisation relation (3) are presented. The causal Markov assumption is the central assumption that defines BN. According to this assumption, each node is independent of its non-descendants in the graph, conditional on its parents in the graph. In other words, given a node's immediate cause, we can disregard the causes of its ancestors.

Next one very important definition for the DAG and $\mathrm{BN}$, which is the $d$-separation is discussed. The $d$-separation condition is especially important and useful in constructing a $\mathrm{BN}$ because it controls for possible confounds as in the form of $S$ described here. In other words, a set of variables $S, d$-separate variable $X$ from $Y$, if and only if $S$ blocks every path from $X$ to $Y$. 
Graphically, $d$-separation usually exhibits two main cases: firstly $X \rightarrow S \rightarrow Y$ and secondly $X \leftarrow S \rightarrow Y$. The intuition behind this graphical representation is that $X$ and $Y$ are independent from each other conditioned on $S$. In the first case $X$ causes $Y$ through $S$, while in the second case $X$ and $Y$ have a common cause $S$. To ascertain whether a particular conditional independence statement $X \perp Y \mid S$ is implied the possible paths from any node in $X$ to any node in $Y$ are considered. Any such path is blocked if it includes a node such that either the arrows on the path meet either head-to-tail or tail-to-tail at the node, and the node is in $S$, such as the relations $X \rightarrow S \rightarrow Y$ and $X \leftarrow S \rightarrow Y$ or the arrows meet head-to-head at the node, and neither the node, nor any of its descendants, is in $S$. If all paths are blocked, $X$ is d-separated from $Y$ given $S$, and the joint distribution over all of the variables in the graph will then satisfy $X \perp Y \mid S$.

Definition 1. (Partial Correlation): For $i \neq j \in 1, \ldots, p, k \in X_{r}$, let $\rho_{i, j \mid k}$ be the partial correlation between $X_{i}$ and $X_{j}$ given $X_{r}$ and $X_{r}$ denotes the rest of the variables.

Based on this definition we have that $X_{i} \perp \perp X_{j} \mid X_{r} \Leftrightarrow \rho_{i, j \mid k}$. Next the Fisher's $\mathrm{Z}$ test for the conditional independence is presented (Spirtes et al., 2000; Kalisch and Buhlmann, 2007):

$\rho_{X Y \mid C}=0$

$$
z\left(\rho_{X Y \mid C^{, n}}\right)=\frac{1}{2} \sqrt{n-|C|-3} \log \frac{\left(\left|1+\rho_{X Y \mid C}\right|\right)}{\left(\left|1-\rho_{X Y \mid C}\right|\right)}
$$

$|C|$ is the number of variables in $C$ and $n$ is the length of the sample. If $X, Y, C \sim N$ under the null hypothesis of zero partial correlation:

$$
z\left(\hat{\rho}_{X Y \mid C^{n}}\right) \sim N(0,1)
$$


The test for independence is based on the PC algorithm (Spirtes et al., 2000) at significance level $\alpha$. Kalisch and Buhlmann (2007) show that the choice of $\alpha$ is not too important. However, the significance level $\alpha=0.05$ is used. The pseudo-code of the PC algorithm is presented in figure 5.

\section{(Insert Figure 5)}

Next this section discusses the possibilities of using the DAG and $\mathrm{BN}$ as a tool for discovering candidate instrumental variables. A DAG representation where an instrumental variable $I$ can meet the conditions and which can be used into the analysis is presented in figure 6, where the instrumental variable $I$ is related to the cause of interest $X$ and influences $Y$ only through its impact on $X$ and at least one control variable blocks the other path, such the variablenode $S$, which can be also a set of variables $\mathbf{S}$. As it can be seen in figure 6 , in order to use variable $I$ as an instrument, we should condition on $S$ but not on $W$, because it is descendant of $Y$ and the common cause of $W$ coming from $I$ and $Y$ will lead to selection bias as we described in the methodology part and considering the $d$-separation condition. More specifically, a variable $I$ qualifies as an IV for $X$ (factor of interest) and $Y$ (outcome of interest if the following three conditions are met: a) $I$ is statistically independent of all joint common causes of $X$ and $Y$; b) $I$ is not independent of $X$; and c) the effect of $Z$ on $Y$ is mediated solely by $X$.

\section{(Insert Figure 6)}

Lemma 1. Given a path diagram $G$ and which contains the direct edge $X \rightarrow Y$, then a variable $I$ can be an instrumental variable for $X$ given $Z$, which is a set of variables that does not contain any variable from $I, X, Y$, or Desc $(Y)$ if the following conditions are met:

- In the path diagram $\mathrm{G}, \mathrm{X}$ and I are connected given $\mathrm{Z}$

- In the path diagram $\mathrm{G}_{\mathrm{X} \rightarrow \mathrm{Y}}$ which is formed by removing $\mathrm{X} \rightarrow \mathrm{Y}$ from $\mathrm{G}$, I and $\mathrm{Y}$ are dseparated given $\mathrm{Z}$.

Then the direct causal effect $\tau_{y x}$ is given by: 


$$
\tau_{y x}=\frac{\sigma_{I Y \cdot Z}}{\sigma_{I X \cdot Z}}
$$

Lemma 1 can be extended into a set of instrumental variables $I_{i}$ for $i=1, \ldots, k$. In that case the direct causal effects $\tau_{y x_{1}}, \ldots \ldots ., \tau_{y x_{k}}$ can be solved by a system of $k$ equations as:

$$
\begin{gathered}
\sigma_{I_{i} Y \cdot Z}=\sum_{j=1}^{k} \sigma_{I_{i} X_{j} \cdot Z} \tau_{Y X_{j}} \\
, \text { for } i=1, \ldots k
\end{gathered}
$$

For instance when $X \perp Y$ then it is $\operatorname{cov}(X, Y)=0$. In relation (8), $\sigma_{I Y . Z}$ is the conditional covariance between $I$ and $Y$ given $Z=z$, while similarly $\sigma_{I X . Z}$ is defined as the conditional covariance between $I$ and $X$ given $Z=z$. Considering the $\operatorname{Cov}(\mathrm{I}, \mathrm{Y} \mid \mathrm{Z})$ it will be:

$$
\begin{aligned}
& E[I, Y \mid Z]-E[I \mid Z] E[Y \mid Z]= \\
& E[(I, Y-E[I \mid Z] Y-I E[Y \mid Z]+E[I \mid Z] E[I \mid Z]) \mid Z]= \\
& E[I, Y \mid Z]-E[I \mid Z] E[Y \mid Z]-E[I \mid Z][Y \mid Z]+E[I \mid Z] E[Y \mid Z]= \\
& E[I, Y \mid Z]-E[I \mid Z] E[Y \mid Z]
\end{aligned}
$$

In a similar fashion the $\operatorname{Cov}(\mathrm{I}, \mathrm{X} \mid \mathrm{Z})$ we will have:

$$
E[I, X \mid Z]-E[I \mid Z] E[X \mid Z]
$$

Thus, this test can be applied in other studies using IV approach and to define whether the IV is proper or not, especially regarding the selection bias. Plugging (10)-(11) in (8) it will be:

$$
\tau_{y x}=\frac{\operatorname{Cov}[I, Y \mid Z]}{\operatorname{Cov}[I, X \mid Z]}
$$

And equivalently becomes:

$$
\tau_{y x}=\frac{E[I, Y \mid Z]-E[I \mid Z] E[Y \mid Z]}{E[I, X \mid Z]-E[I \mid Z] E[X \mid Z]}
$$


Concluding the causal effect of the IV-DAG will be the same with the traditional IV with the difference that the factors of interest (employee arrangements), the outcomes of interest (job satisfaction and employee loyalty) and the instrumental variables should be conditioned on a specific set of variables $\mathbf{Z}$. Relationships $10-13$ can be considered under the total covariance and its decomposition, so the first term of the numerator (or denominator respectively) shows the within group or the average of the covariances $X$ and $Y$ evaluated for each group, and the second term is the between group or the group-averages for $X$ and $Y$.

Overall, as we discussed earlier, the main aim of this study is to examine if there is a causal effect from the flexible employment schemes on job satisfaction and employee loyalty. The fixed effects models can solve for endogeneity coming from omitted variables bias, but not for the possible reverse causality between flexible employment and job satisfaction, where the more or less satisfied employees may seek the specific flexible employment types. Therefore, the BN framework using instrumental variables is suggested in this study.

\subsection{Data}

The Workplace Employment Relations Study (WERS) series commenced in 1980 and took place six times until 2011. The 2004 and 2011 Panel Survey was conducted in a random subsample of workplaces and the surveys are conducted to managers and employees. This is useful

for the analysis, since the regressions control not only for employee characteristics, but also for firm characteristics, such as competition and market area.

The first outcome of interest is the job satisfaction, which is an ordered variable measured in a Likert scale from 1 (very dissatisfied) to 5 (very satisfied). Similarly, employee loyalty is an 
ordered variable answering to the question "To what extent do you agree or disagree with the statement that you are loyal to your firm-organisation" measured in a scale from 1 (strongly disagree) to 5 (strongly agree). In table 1 we present the summary statistics for the outcomes of interest-job satisfaction and employee retention- and the factors of interest which are the employment arrangements explored in this study. The average job satisfaction and employee loyalty levels are relatively high to our sample with average very close to 4 . Regarding the employment arrangements explored in this study, the lowest percentage of participation belongs to teleworking.

Additional variables are not presented, as the descriptive statistics do not give any additional insights. For this reason we show the correlation matrix among the outcomes of interest and the employment arrangements in table 2 . In all cases there is a positive relationship among the two types of employment, and a positive association between employee loyalty, job satisfaction and those employment types. Additional factors are not explored as they are used as controls in to the regressions; however, some correlation statistics show for instance that wage and higher education degree are positively associated with flexi time and teleworking.

(Insert Tables 1-2)

\section{Empirical Results}

\subsection{OLS Estimates}

The OLS estimates after the propensity score matching are presented in table 3 . The results show that the relationship between job satisfaction and the employment arrangements explored is 
positive and significant. The highest magnitudes are presented in the case of the teleworkers, followed by those who implement flexi time.

Next we describe the estimates for the remained covariates. We observe that female workers are more satisfied with their job and this difference can be explained by the fact that men and women have different expectations from their jobs (Clark, 1997; Gazioglu and Tansel, 2006). Our estimates show that there is a non-monotonic pattern of the age-job satisfaction relationship and specifically a U shaped curve, where young aged groups 18-21 are less satisfied and a positive coefficient for the age group 60-64. Earlier studies support this pattern and they provide four main factors of its explanation. First, young workers they have little experience about the labour market and conditions and have more expectations that are not met from their jobs. Second, older employees may have reduced aspirations because they realise that they face more limitations and restrictions of reaching a specific point of achievements in their career. Third, older workers may have already accomplished their expectations compared to younger workers. Fourth, high levels of job satisfaction can be a self-selection effect, as dissatisfied older employees may find it easier to leave the labour market, and therefore, the majority of the older employees remaining at the job can be satisfied with their job (Clark, 1996; Clark et al., 1996; Gazioglu and Tansel, 2006).

This pattern is also consistent with the education and matching skills to job. More specifically, those with first degree in some cases report lower levels of job satisfaction, which is consistent with other studies, arguing that more educated people have higher expectations about their pecuniary and non-pecuniary returns form their job and thus are more easily disappointed and dissatisfied (Clark and Oswald, 1996; Hamermesh, 2000; Giovanis and Ozdamar, 2016). The same applies with the matching skills to job. More precisely, those who stated that their skills 
match the job almost the same or bit lower report higher levels of job satisfaction than those who stated that are over-qualified. As we discussed in the methodology section, increases in the expectations of the high educated employees that do not meet the job requirements and the expected outcomes in the labour market, the relationship between job satisfaction and education becomes negative.

Marital status may present mixed results as earlier studies illustrate. A number of studies found that overall married couples are happier with their lives, which may have also an impact on the job satisfaction (Clark, 1996; Giovanis and Ozdamar, 2016). However, we show that there is no difference between the single, married, and widowed employees, but divorced workers are more satisfied than singles, which deserves more attention in future studies. Earlier studies provide mixed effects, where Clark (1996) found that the married employees are more satisfied, while Gazioglu and Tansel (2006) report that married employees are less satisfied compared to singles.

The estimates in table 3 illustrate a positive and linear relationship between wage and job satisfaction, where it is insignificant in the low wage scales and it becomes significant in the high salary scales. The estimated coefficients of supervising other employees and being no-member of a trade union are positive and significant. While a possible explanation for the supervision is that people who supervise may enjoy higher wages, expectations and the ability to implement flexible employment schedules that in turn lead to higher job satisfaction, there is no clear explanation for the positive sign of the non-membership in a trade union, which can be investigated further in research applications. This relationship is confirmed also in the study by Gazioglu and Tansel (2006) who found a significant negative relationship between union membership and job 
satisfaction which may indicate an issue of endogeneity, because dissatisfied employees are more likely to join the unions.

Next we present the results about the firm related characteristics. As we discussed in the methodology section, the impact of performance appraisal, performance related payments and the quality of manager-employee relations is significant on both job satisfaction and employee loyalty. The study by Tansel and Gazioglu (2006) supports that the quality of employee relations is positively associated with job satisfaction and it is also confirmed by our findings. Earlier studies have not explored these determinants, but employees who perform better receive bonus and additional earnings which enhance their job satisfaction and their loyalty to the firm.

A factor that is not included in our regression analysis is the firm size. In a study by Tansel and Gazioglu (2014) the firm size, which is proxied by the number of employees, was found to be negatively associated with job satisfaction using the same survey-WERS- in 1997. We have included the number of employees in our regressions; however, their coefficients are insignificant in all cases and excluding this variable does not have an impact on the remained estimated coefficients. Nevertheless, as a proxy for firm size we included the area where the company is operated, and specifically whether the firm's operations are limited only to local areas, or are expanded in regional, national and international locations. This may not be the best measure of firm size; however, firm size can be measured by sales volume, employment growth and usually international firms are larger considering this aspect. On the other hand, the number of employees does not indicate or measure always the firm size, as a specific workplace may employ a high number of people, but its operations are limited only to local areas and the sales, including other monetary measures, can be significantly lower compared to national and international workplaces. 
As we observe, employees working in regional and international workplaces are more satisfied and loyal compared to local firms. Regarding the competition and the firm status, we show that there is no difference among the number of establishments, whether the workplace faces competition from abroad, and whether is private or public. The exception is the employees who work in foreign but UK based company and those who work in government-own limited companies who are less loyal compared to single and public companies. The explanation of the estimated coefficients for the market area may vary. First, national or international companies may probably more likely to offer flexible working schedules. More specifically, from the survey we conclude that the proportion of flexi-time and home teleworkers in international companies is respectively 52 and 23 per cent, while the respective percentages in local companies are 39 and 9. This is in line with the estimates that flexible employment increases job satisfaction and loyalty. Another possible explanation can be the reputation of the workplaces or the job security and the competition. Large firms offer the opportunity to employees to work in organisations with high reputation, accompanied with higher wages, more expectations and chances of promotion to higher ranking levels within the workplace, lower firm competition and job security. Furthermore, this can be result of selection or over-control bias, since we include the competition and the number of establishments, but these are issues that can be solved within the BN framework.

Earlier studies found such mixed results about the relationship between job satisfaction and firm size that simple relationship models does not seem to be sufficient. A number of studies found a negative relationship (Dunn, 1980; Idson, 1990; Clark, 1996; Tansel and Gazioglu, 2014), while other studies show a positive association (Osborne and Hunt, 1972; Hodson, 1989). García-Serrano (2011) finds no statistical differences when the regressions control for working 
conditions. Even though small firms cannot offer higher wages and the reputation of the organisation's brand name among other tangible and intangible benefits (Brown and Medoff, 1989), still is not clear why the personal growth and autonomy motivators that are theoretically strong in the small firms (Talacchi, 1960; Ingham, 1970; Lang and Johnson, 1994) do not actually enhance the overall job satisfaction. However, we are not able to infer in-depth analysis and investigations, since it is out of the current study's topic, but we suggest it for future research. The study by Lang and Johnson (1994) offers a good point to investigate the relationship between firm size and satisfaction considering the intrinsic and extrinsic values.

Similarly in table 4 the relationship between employee loyalty and the employment arrangements is significant. The remained controls are not reported as the conclusions are similar. Furthermore, the variables of whether the respondent has at least one dependent child aged 0-2 years old or older and the percentage of the employees using computer in the firm are included. In all cases the coefficients are insignificant, suggesting that these variables can be used as instruments since are not correlated with the outcome. However, other variables are not also significant, but they might be necessary to be employed as controls-or parents-using the terminology of BN. More specifically, relation (13) implies that the IV approach should consider certain variables that can be used as controls, as it will be shown later in this part.

In table 5 the Ordered Probit estimates for the two employment arrangements are reported. The positive and significant coefficient of flexi-time and teleworking is presented; however the magnitude is higher since the Ordered Probit models follows a different empirical estimation procedure than OLS.

(Insert Tables 3-5) 


\subsection{BN and DAG Estimates}

In this section we present and discuss the results derived by the BN methodology, but also the estimates using IV approach within BN framework and DAG illustration. In figure 7 we present the estimated DAG for teleworking, while the BN estimates considering both employment arrangements explored in the study, are reported in table 6. A similar representation is observed for the remained of the employment types, but their associated DAGs are not presented here. In addition, separate estimates for each employment arrangements is taking place, since it is difficult to disentangle their effects, when they are included into the same regression. The reason is that regression presents over-control bias where some variables block the causal effect from the variable of interest to the outcome. For instance coming back to figure $4, F$ blocks-off the causal effect from $T$ to $Y$ since there is no direct effect (arrow) from the former to the latter. Similarly, in this case teleworking may block -off the causal effect from flexi-time to job satisfaction. Thus, one solution is to not include them in to the same DAG, while the second solution is to incorporate them into the same DAG and $\mathrm{BN}$ and applying the factorisation relation (3) wherever necessarily.

Before we proceed to the main concluding remarks of our findings, the abbreviations of the variables in the DAG figure 7 are described. Variables ethnic, mastat, superv_other, num_hours and age indicate respectively ethnicity, marital status, supervising other employees, number of weekly hours worked and age. The other variables have as following: dependent children 0-2 years old (dep_chil_0_2), years worked (years_exp), education level (education), status of company (status_com), marital status (mastat), number of firm establishments (single_ind), whether the skills match to employee's work (skill_job), area market of the firm (market_ope), 
TTWA (area), quality of relations between managers and employees (rel_mang_emp), wage (wage), percentage of employees in the firm using computer (computer_use), whether the employee is member of union trade or staff association (union_memb), formal written policies for equal opportunities in the institution (policy_dis), performance pay schemes (perf_pay), related profit schemes (related_prof), proportion of non-managerial staff under performance evaluation (prop_non_man_eval) home-teleworkers (home_tele_work), job satisfaction (job_sat) employee loyalty (loyal).

Applying the factorisation model (4) and the d-separation the causal effect of the teleworking on job satisfaction is a regression of itself and its parents-computer_use, wage, education, union_memb,rel_mang_emp, skill_job and superv_other. More specifically, in columns (1)-(2) of table 6 the OLS estimates for flexi-time and teleworking are respectively presented. Similarly, in columns (3)-(4) the respective ordered Probit (OP) results are reported. In Panel A the dependent variable is job satisfaction, while in Panel B the dependent variable is employee loyalty.

The causal effect of teleworking on job satisfaction and employee loyalty is higher than those found in tables 3-5. More specifically, according to BNs the coefficients for job satisfaction and employee loyalty are 0.1671 and 0.1503 , while the respective coefficients with OLS are 0.1437 and 0.1158 lower by $15-23$ per cent. A similar DAG is estimated for the flexi time; however is not presented here, but its causal effects are reported in table 6. More precisely, the effects on job satisfaction and employee loyalty are underestimated by $7-15$ per cent.

Various other conclusions can be derived from DAG in figure 7. For instance, the regression should not condition on employee loyalty since it is caused by both job satisfaction and teleworking, leading to selection bias. Similarly, if we would like to derive the causal effect of 
wage on job satisfaction, a regression including the wage and its parents will take place. Another example is the computer use, where its causal effect is blocked-off by teleworking. In this case also the regression should include the computer use and its parents, in order to estimate the causal effect of computer percentage use on job satisfaction. However, two things are concluded. First, conditioning on teleworking, the causal effect of computer use is blocked-off from teleworking leading to over-control bias, as we discussed in the methodology section and since there is no direct effect-arrow to job satisfaction. Thus, in this case the front-door and back-door criteria are applied.

Second, coming back to the figure 7 , computer use can be used as an instrumental variable because is directly related to teleworking, and is conditioned on related_prof which the latter affects the job satisfaction. Thus, the IV should be conditioned on at least one other variable which causes job satisfaction. In this case, according to table 7 and the 2SLS estimates in column (2), the causal effect of teleworking on job satisfaction employing as instrument to teleworking the percentage of employees using computer in the institution-firm is 0.1988. For the flexi-time working arrangement, based on the $\mathrm{BN}$ the same instrumental variable is employed, as well as, whether there is dependent child 0-2 years old in the employee's family. In all cases the estimates confirm the impact of these working schedules on job satisfaction and employee loyalty which is 0.1751 , and is higher compared to the previous estimates. Similarly, the effects of teleworking on job satisfaction and employee loyalty is found equal at 0.1988 and 0.1779 respectively which are 38 and 53 percent higher than the respective estimates found by OLS. In columns (3)-(4) the IV-DAG estimates are reported. As we discussed in the methodology section, the IV-DAG regressions are similar with the 2SLS with the difference that the factors of interest, which is flexi time and teleworking, are conditioned on a specific set of variables $\mathbf{Z}$. 
This is more proper since the DAG can account for the three types of biases discussed in the methodology section. As an example we turn back to relation (13) and we substitute the values for teleworking in table 7 and column (4) and we find:

$\tau_{y x}=\frac{E[I, Y \mid Z]-E[I \mid Z] E[Y \mid Z]}{E[I, X \mid Z]-E[I \mid Z] E[X \mid Z]}=\frac{0.0837+0.0373}{0.532+0.0940}=\frac{0.121}{0.626}=0.193$

Similarly for teleworking and employee loyalty in panel B of table 7 and column (4):

$$
\tau_{y x}=\frac{E[I, Y \mid Z]-E[I \mid Z] E[Y \mid Z]}{E[I, X \mid Z]-E[I \mid Z] E[X \mid Z]}=\frac{0.062+0.002}{0 . .357+0.0152}=\frac{0.064}{0.372}=0.172
$$

A similar exercise takes place for the flexi-time. Overall, BN can be a very useful tool for empirical research allowing us to find proper instrumental variables wherever possible. However, the results confirm that IVs are not always necessarily to be considered and analysed into a $\mathrm{BN}$ framework to infer causality. Another point that we should notice is that in many studies the principal component analysis (PCA) is used to reduce the number of variables into the analysis. However, PCA is based on assumptions which are not always met. More specifically, the first assumption is that the dimensionality of data can be efficiently reduced by linear transformation, but this is not always the case, since points of an input set are positioned on the surface of a hypersphere, and no linear transformation can reduce dimension. The second drawback of PCA is the fact that directions maximising variance do not always also optimise information. BN is not limited from these assumptions and it allows us to decide which variables should be included into the regressions analysis without losing information (Lee et al., 2012; Karamizadeh, 2013). Moreover, the interpretation can be more difficult since we are not working 
with the original variables and the principal components are heavily affected by the scaling of the variables.

\author{
(Insert Tables 6-7)
}

\title{
4.3 Discussions
}

Since the job satisfaction and employee retention have a central role to firm's organisation and policy, but also are topics of the policy makers' agenda for the improvement of the society's well-being, Bayesian networks can have important policy implications, as causal inference has a central role in well-being and policy making. These implications can be extended and applied in many other domains of well-being and public policy, including life satisfaction, leisure and public health among others. Since the natural experiments are very difficult to be found and many times may not be under the researcher's control and instrumental variables are very difficult to be found and be convincible, Bayesian Networks is an alternative tool which can be useful, when the former cases are absent. BNs can be applied not only to observational data, which are very useful for controlling for various characteristics; where in the majority of the natural experiments are missed. Moreover, $\mathrm{BN}$ can be applied also to randomised experiments (Pearl, 2000, 2009; Spirtes et al., 2000). The methodology framework followed in this study suggests that $\mathrm{BN}$ can be a valuable instrument for deriving plausible causal effects using observational data, and it provides a very useful graphical representation which allows us to consider the three types of bias discussed before; the over-control, confounding and selection bias. Moreover, BN and DAGs can be a valuable tool for testing and obtaining candidate variables as instruments to the factor of interest, which were the employment arrangements in 
this study. Furthermore, DAGs allows us to account for selection bias when a variable is chosen as instrument. For instance, it has been discussed that a variable which is a descendant of both factors of interest (employment arrangements in this case) and the outcomes of interest (job satisfaction or employee loyalty) cannot be considered as instrument, since it is correlated or affected by both employment arrangements and the outcome.

However, there are various drawbacks in our analysis that have to be considered in future research studies and applications. First and most important, our sample consists of a workplace and not employee panel that does not allow us to include the history of workers into a fixed effects model. Second, the workplace panel data structure is limited only in two periods, 2004 and 2011, where in the case that explanatory variables of main interest are not exogenous and the coefficients are heterogeneous, then there is a large issue of identification. Third, applying the BN methodology or using IV even within the BN framework and DAG analysis, at the best case we derive the local average treatment effect (LATE) since we condition the treatmentendogenous variable on the distribution of the instrument or whether the instrument is "activated", taking value 1. For example, for flexi-time we considered a dummy variable whether the respondent has dependent children, and assuming that the individuals would choose the treatment- flexible employment schemes- if the instrument takes a value of one. In other words the LATE achieved by IV and IV-DAG, might be better than nothing, but it provides consistent estimates of the average treatment effect only for a sub-group of the total population; the socalled "compliers" and not the average total effects (ATE) of the whole population. (Angrist and Evans, 1998). On the other hand, it is possible to identify the average effect using the BN methodology with limiting the sample or conditioning only on a sub-group. Nevertheless, the LATE issue is observed also in Randomised Controlled Trials (RCTs) and it is a common 
characteristic in these approaches. However, we proposed BN as an alternative method that shows clearly and graphically the relationships among the variables which is impossible with the conventional statistical and econometric models.

\section{Conclusions}

The results in this paper support the following propositions. First, there is a positive effect from the two employment arrangements examined, on job satisfaction and employee loyalty. This may indicate that these types of employment can allow the employees to use them as means of relief from stressful conditions, coming mainly from commuting at work and the traffic congestion. Moreover, these types of working arrangements, may give to employees more autonomy and control of the working schedule and to allow them to adjust it on their needs, including family demands and obligations and leisure activities. Furthermore, future research can take place exploring how these employment arrangements improve the labour productivity and the firm performance, through job satisfaction, as well as, how much costs are saved in terms of office, equipment and other labour related expenses. In addition, this study showed that in the case of the flexible working schedules implementation and especially the employees, who are involved in teleworking, are more likely to report higher levels of loyalty than those who do not implement them. Second, the results show that wage, the quality of manager-employee relations, performance related payments and the market area are important factors of job satisfaction. The findings of this study have important policy implications for the business managers. By implementing flexible employment schemes, including teleworking and homeworking and improving the management-employee relations will not only increase employee satisfaction, but it will also increase productivity and employee loyalty and therefore will reduce the turnover 
intentions. Third, the findings support and confirm earlier studies that use access to computer or internet at home as an instrument for homeworking, by proposing and implementing an IV approach within the BN framework. This methodological tool can be applied also to future studies for confirming the suitability of the instrument used and especially when it is difficult to find legitimate instruments.

Overall, managing turnover intention is a challenge for many organisations that incur very high costs as a result of voluntary turnover and retaining good workers is critical to any organisation, public or private. Thus, flexible employment arrangements, including teleworking can be a solution to turnover intention reduction, increasing the job satisfaction and improving the well-being of employees. However, most of these issues have not been examined here but are proposed for future research and applications. Another concluding remark of this study is that BN and DAG, offer an alternative way of deriving causality using observational data and surveys, with various policy implications and implementations to workplaces, employees, employers and to the society overall. Finally, the study presented and discussed an alternative way of identifying possible candidate instrumental variables using the BN and DAG framework, which otherwise can be difficult if not impossible.

\section{Acknowledgments}

This work was supported by the Marie Skłodowska-Curie Individual Fellowship (IF) grant [652938-TELE]. The author gratefully acknowledges the funding provided by European Commission to carry out this research.

The author would like to thank the anonymous reviewers for their valuable comments, suggestions and constructive comments that greatly contributed to the improvement of the quality of this paper. Any remaining errors or omissions remain the responsibility of the author.

This study used panel data from the 2004 and 2011 Workplace Employment Relations Surveys (WERS). The WERS was conducted by NatCen Social Research on behalf of the Department for Business, Innovation and Skills, the Economic and Social Research Council, the UK 
Commission for Employment and Skills, the Advisory, Conciliation and Arbitration Service and the National Institute of Economic and Social Research. The data was distributed by the UK Data Archive at the University of Essex.

\section{References}

Angrist, J. D. and Evans, W. N. (1998) 'Children and their Parents' Labor Supply: Evidence from Exogenous variation in family size', American Economic Review, Vol. 88, No. 3, pp. 450-477.

Bailyn, L. (1988) 'Freeing Work from the Constraints of Location and Time', New Technology, Work, and Employment, Vol. 3, No. 2, pp. 143-152.

Baltes, B.B., Briggs, T.E., Huff, J.W., Wright, J.A. and Neuman, G.A. (1999) 'Flexible and compressed workweek schedules: A meta-analysis of their effects on work-related criteria', Journal of Applied Psychology, Vol. 84, No. 4, pp. 496-513.

Bélanger, F. (1999) 'Workers' propensity to telecommute: An empirical study', Information Management, Vol. 35, No. 3, pp. 139-153.

Brown, C. and Medoff, J. (1989) 'The employer size-wage effect', Journal of Political Economy, Vol. 97, No. 5, pp. 1027-1059.

Burgoon, J.K., Bonito, J.A., Ramirez, A., Dunbar, N.E., Kam, K. and Fischer, J. (2002) 'Testing the interactivity principle: Effects of mediation, propinquity, and verbal and nonverbal modalities in interpersonal interaction', Journal of Communication, Vol. 52, No. 3, pp. 657677.

Christensen, K.E. and Staines, G.L. (1990) 'Flextime: A viable solution to work/family conflict?' Journal of Family Issues, Vol. 11, No. 4, pp. 455-476.

Clark, A. E. (1996) 'Job Satisfaction in Britain', British Journal of Industrial Relations, Vol. 34 No. 2, pp.189-217.

Clark, A.E. and Oswald, A.J. (1996) 'Satisfaction and Comparison Income', Journal of Public Economics, Vol. 61, No. 3, pp. 350-381.

Clark, A. E., Oswald, A. and Warr, P. (1996) 'Is Job Satisfaction U-Shaped in Age?' Journal of Occupational and Organizational Psychology. Vol. 69, No. 1, pp.57-81.

Clark, A. E. (1997) 'Job Satisfaction and Gender: Why are Women so Happy at Work', Labour Economics, Vol. 4, No. 4, pp. 341-372.

Crandall, W. and Gao, L. (2005) 'An update on telecommuting: Review and prospects for emerging issues', S.A.M. Advanced Management Journal, Vol. 70, No. 3, pp. 30-37.

Dunn, L. F. (1980) 'The Effects of Firm and Plant Size on Employee Well-Being" in The Economics of Firm Size,' Market Structure and Social Performance (Ed.) J. J. Siegfried, Federal Trade Commission, Washington DC.

Estes, S.B. (2005) 'Work-family arrangements and parenting: Are family-friendly arrangements related to involved in children's lives?' Sociological Perspectives, Vol. 48, No. 3, pp. 293317.

Ferrer-i-Carbonell, A. and van Praag, B.M.S. (2004) Happiness Quantified: A Satisfaction Calculus Approach. Oxford : Oxford University Press, 2004.

Ferrer-i-Carbonell, A. and Frijters, P. (2004) 'How Important Is Methodology for the Estimates of the Determinants of Happiness?' Economic Journal, Vol. 114, No. 497, pp. 641-659. 
Fonner, K.L. and Roloff, M.E. (2010) 'Why teleworkers are more satisfied with their jobs than are office-based workers: When less contact is beneficial', Journal of Applied Communication Research, Vol. 38, No. 4, pp. 336-361.

Frone, M.R. and Yardley, J.K. (1996) 'Workplace family-supportive programmes: Predictors of employed parents' importance ratings', Journal of Occupational and Organizational Psychology, Vol. 69, No. 4, pp. 351-366.

Gajendran, R.S. and Harrison, D.A. (2007) 'The good, the bad, and the unknown about telecommuting: Meta-analysis of psychological mediators and individual consequences', Journal of Applied Psychology, Vol. 92, No. 6, pp. 1524-1521.

Galinsky, E., Bond, J.T. and Freidman, D.E. (1996) 'The role of employers in addressing the needs of employed parents', Journal of Social Issues, Vol. 53, No. 3, 111-136.

García-Serrano, C. (2011) 'Does The Size Matter? The Influence of Firm Size on Working Conditions and Job Satisfaction', Scottish Journal of Political Economy, Vol. 58, No. 2, pp. 221-247.

Garen, J. (1988) 'Compensating wage differentials and the endogeneity of job Riskiness', The Review of Economics and Statistics, Vol. 70, No. 1, pp. 9-16.

Gazioglu, S. and Tansel, A. (2006) 'Job satisfaction in Britain: individual and job related factors', Applied Economics, Vol. 38, No. 10, pp. 1163-1171.

Giovanis, E. and Ozdamar, O. (2016) 'Structural Equation Modelling and the Causal Effect of Permanent Income on Life Satisfaction: The Case of Air Pollution Valuation in Switzerland', Journal of Economics Surveys, Vol. 30, No. 3, pp. 430-459.

Golden, T.D. and Veiga, J. F. (2015) 'The impact of extent of telecommuting on job satisfaction: Resolving inconsistent findings', Journal of Management, Vol. 31, No.2, pp. 301- 318.

Golden, T.D., Veiga, J.F. and Simsek, Z. (2006) 'Telecommutings differential impact on workfamily conflict: Is there no place like home?' Journal of Applied Psychology, Vol. 91, No.6, pp. 1340-1350.

Gronlund, A. (2007). 'More control, less conflict? Job demand- control, gender and work-family conflict', Gender work and organization, Vol. 14, No. 5, pp. 476-497.

Hamermesh, D.S. (2000) 'The changing distribution of job satisfaction', Journal of Human Resources, Vol. 36, No. 1, pp. 1-30.

Heckerman, D.E. (1997) 'Bayesian networks for data mining', Data Mining and Knowledge Discovery, Vol. 1, No. 1, pp. 79-119.

Hodson, R. (1989) 'Gender differences in job satisfaction: Why aren't women more dissatisfied?' The Sociological Quarterly, Vol. 30, No. 3, pp. 385-399.

Idson, T. L. (1990) 'Firm Size, Job Satisfaction and the Structure of Work', Applied Economics, Vol.22, No. 8, pp. 1007-1018.

Ingham, G.K. (1970) Size of Industrial Organisation and Worker Behaviour. Cambridge: Cambridge University Press, UK.

Jiang, Y. (2008) The impact of telecommuting on the journey to work: A two sample instrumental variables approach. Two empirical essays in environmental and urban economics. Ph.D. Thesis, University of Maryland: ProQuest LLC.

Kalisch, M. and Buhlmann, P. (2007) 'Estimating High-Dimensional Directed Acyclic Graphs with “ the PC-Algorithm', Machine Learning, Vol. 8, No. 3, pp. 613-636.

Karamizadeh, S., Shahidan, M.A., Azizah, A.M., Mazdak, Z. and Hooman, A. (2013) 'An Overview of Principal Component Analysis', Journal of Signal and Information Processing, Vol. 4, No. 3B, pp. 173-175. 
Karasek, R. A. and Theorell, T. (1990) Healthy work: Stress, productivity, and the reconstruction of working life. New York: Basic Books.

Kelly, E. L. and Moen, P. (2007) 'Rethinking the Clockwork of Work: Why Schedule Control May Pay Off at work and at home', Advances in Developing Human Resources, Special Issue on Work-Life Integration., Vol. 11, No. 9, pp. 487-506.

Kossek, E. E., Lautsch, B.A. and Eaton S.C. (2006) 'Telecommuting, control, and boundary management: Correlates of policy use and practice, job control, and work-family effectiveness', Journal of Vocational Behavior, Vol. 68, pp. 347-367.

Lambert, S. (2000) 'Added benefits: The link between work-life benefits and organizational citizenship behaviour', Academy of Management Journal, Vol. 43, No. 5, pp. 801-815.

Lang, J.R. and Johnson, N.B. (1994) 'Job satisfaction and firm size: An interactionist perspective', The Journal of Socio-Economics, Vol. 23, No. 4, pp. 405-423.

Lee, Y.K., Lee, E.R. and Park, B.U. (2012) 'Principal Component Analysis in very HighDimensional Spaces', Statistica Sinica, Vol. 22, No. 3, pp. 933-956.

Lister, K. and Harnish, T. (2011) 'The state of teleworking in the U.S.: how individuals, businesses, and government benefit', Teleworker Research Network. http://www.workshifting.com/downloads/downloads/Telework-Trends-US.pdf

Lowry, P. B., Roberts, T.L., Romano, N.C., Cheney, P.D. and Hightower, R.T. (2006) 'The impact of group size and social presence on small-group communication: Does computermediated communication make a difference?' Small Group Research, Vol. 37, No. 6, 631661.

Luechinger, S., Meier, S. and Stutzer, A. (2010) 'Why Does Unemployment Hurt the Employed? Evidence from the Life Satisfaction Gap between the Public and the Private Sector', Journal of Human Resources, Vol. 45, No. 4, pp. 998-1045.

Luong, A. and Rogelberg, S. G. (2005) 'Meetings and more meetings: The relationship between meeting load and the daily well-being of employees', Group Dynamics: Theory, Research and Practice, Vol. 9, No. 1, pp. 58-67.

Makin, P. J., Rout, U. and Cooper, C. L. (1988) 'Job satisfaction and occupational stress among general practitioners-a pilot study', Journal of the Royal College of General Practitioners, Vol. 38, No. 312, pp. 303-306.

Mann, S., Varey, R. and Button, W. (2000) 'An exploration of the emotional impact of teleworking via computer-mediated communication. Journal of Managerial Psychology, Vol. 15, No. 7, pp.668_690.

McDonald, P., Guthrie, D., Bradley, L. and Shakespeare-Finch, J. (2005) 'Investigating work family policy aims and employee experiences', Employee Relations, Vol. 27, No. 5, pp. 478494.

Nilles, J.M. (1994). Making telecommuting happen: A guide for telemanagers and telecommuters. New York: John Wiley \& Sons.

Olson, J.S., Teasley, S., Covi, L. and Olson, G. (2002) 'The (currently) unique advantages of collocated work', In P. Hinds and S. Kiesler (Eds.: Distributed work (113-135) Cambridge, MA: MIT Press.

Osborne, R.N. and Hunt, J.G. (1972) 'Relations between leadership, size, and subordinate satisfaction in a voluntary organization', Journal of Applied Psychology, Vol. 60, No. 6, pp. 730-735.

Pearl, J. (1988) Probabilistic Reasoning in Intelligent Systems. San Mateo, California, Morgan Kaufmann. 
Pearl, J. (2000) Causality. Models, Reasoning, and Inference. Cambridge University Press, Cambridge.

Pearl, J. (2009) 'Causal inference in statistics: An overview', Statistical Surveys, Vol. 3, No 1, pp. 96-146.

Potter, E.E. (2003). 'Telecommuting: The future of work, corporate culture, and American society', Journal of Labor Research, Vol. 23, No. 1, pp. 73-83.

Rosenbaum, P.R. and Rubin, D.B. (1983) 'The central role of the propensity score in observational studies for causal effects', Biometrika, Vol. 70, No. 1, pp. 41-55.

Scheffel, J. (2011). 'Identifying the Effect of Temporal Work Flexibility on Parental Time with Children', Deutsche Forschungsgemeinschaft SFB 649 Discussion Paper 2011-024, Berlin, Germany.

Sharpe, D.L., Hermsen, J.M. and Billings, J. (2002) 'Gender differences in use of alternative fulltime work arrangements by married workers', Family and Consumer Sciences Research Journal, Vol. 31, No. 1, pp. 78-111.

Shockley, K.M. and Allen, T.D. (2012) 'Motives for flexible work arrangement use', Community, Work \& Family, Vol. 15, No. 2, pp. 217-231.

Short, J., Williams, E. and Christie, B. (1976) The social psychology of telecommunications. London, UK: Wiley.

Sims, H.P., Szilagyi, A.D. and Keller, R.T. (1976) 'The measurement of job characteristics', Academy of Management Journal, Vol. 19, No. 2, pp. 195-212.

Speier, C., Valacich, J.S. and Vessey, I. (1999) 'Information overload through interruptions: An empirical examination of decision making', Decision Sciences, Vol. 30, No. 2, pp. 337-360.

Spirtes, P., Glymour, C., Scheines, R. (2000) Causation, Prediction, and Search. 2nd ed, MIT Press, Cambridge, MA.

Talacchi, S. (1960) 'Organization size, individual attitudes, and behavior', Administrative Science Quarterly, Vol. 5, No. 3, pp. 398-420.

Tansel, A. and Gazioglu, S. (2014) 'Management-Employee Relations, Firm Size and Job Satisfaction', International Journal of Manpower, Vol. 35, No. 8, pp. 1260-1275.

Velayutham, S. (2013) 'Precarious experiences of Indians in Australia on 457 temporary work visas', Economic and Labour Relations Review, Vol. 24, No. 3, pp. 340-361.

Wilson, S. and Ebert, N. (2013) 'Precarious work: economic, sociological and political perspectives', Economic and Labour Relations Review, Vol. 24, No. 3, pp. 263-279.

WorldatWork. (2011) 'Telework 2011', A WorldatWork Special Report Based on Data Collected by The Dieringer Research Group Inc. and WorldatWork, http://www.worldatwork.org/waw/adimLink?id=53034.

Wright, S. (1921a) 'Systems of Mating. I. The Biometric Relations between Parent and Offspring', Genetics, Vol. 6, No. 2, pp. 111-123.

Wright, S. (1921b) 'Systems of Mating. II. The Effects of Inbreeding on the Genetic Composition of a Population', Genetics, Vol. 6, No. 2, pp. 124-143.

Wright, S. (1921c) 'Systems of Mating. III. Assortative Mating based on Somatic Resemblance', Genetics, Vol. 6, No. 2, pp. 144-161.

Zhu, P. and Mason, S. G. (2014) 'The Impact of Telecommuting on Personal Vehicle Usage and Environmental Sustainability', International Journal of Environmental Science and Technology, Vol. 11, No. 8, pp. 2185-2200. 
Figure 1. Home Teleworking Status by Computer Use

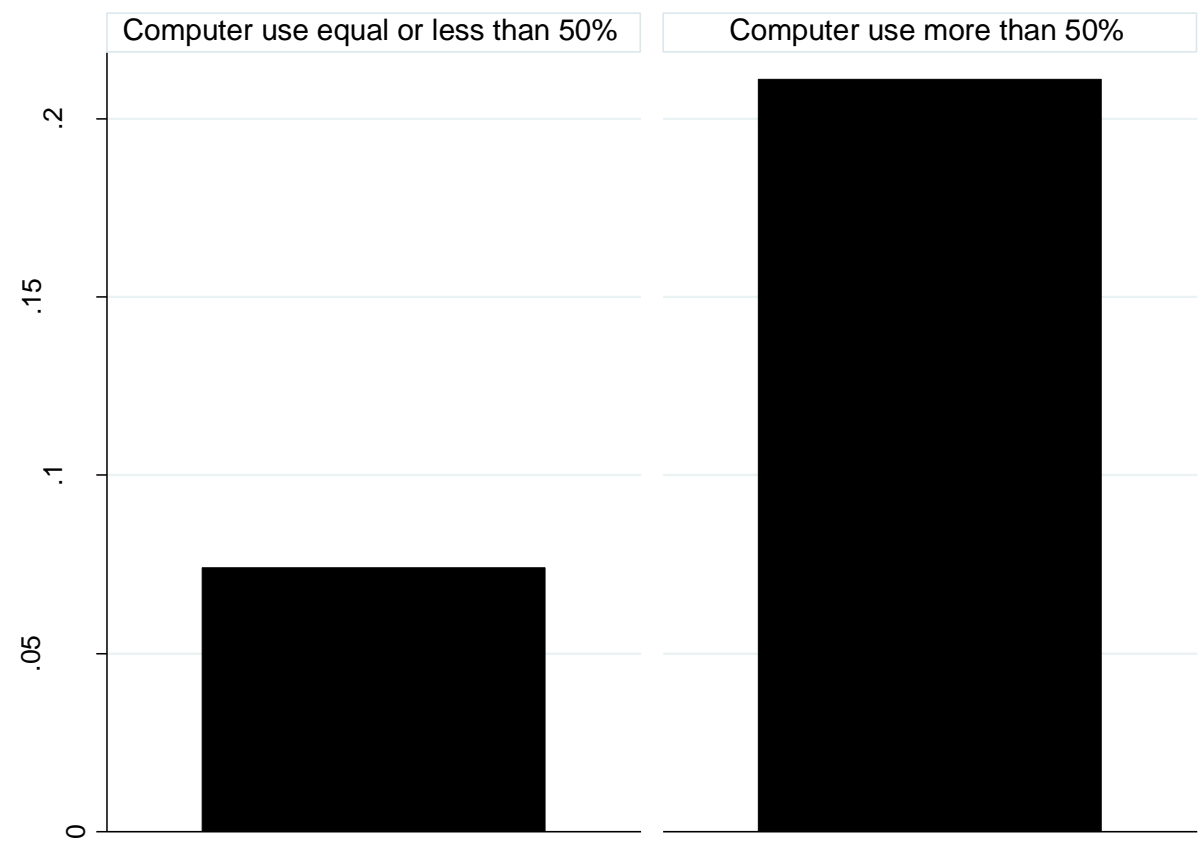

Figure 2. Flexi-time Status by Computer Use

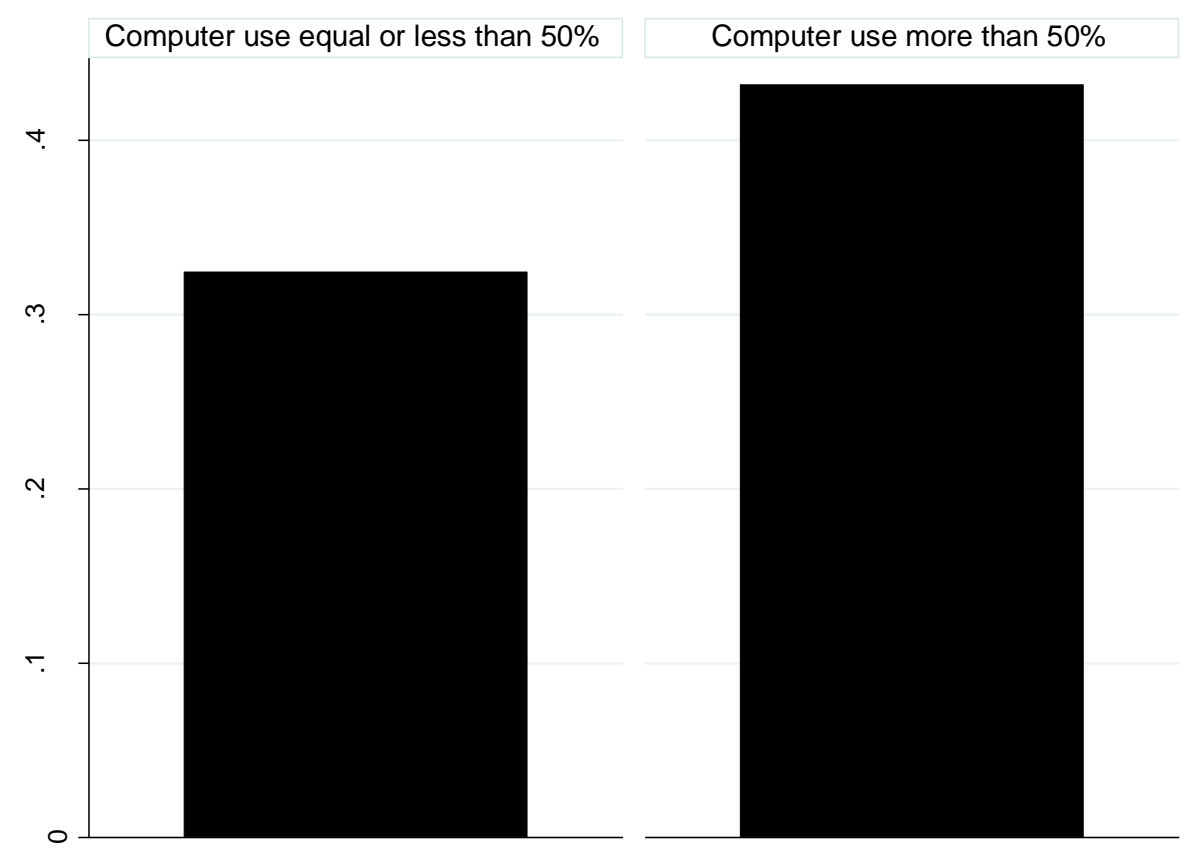


Figure 3. Flexi-time Status by Child Responsibility

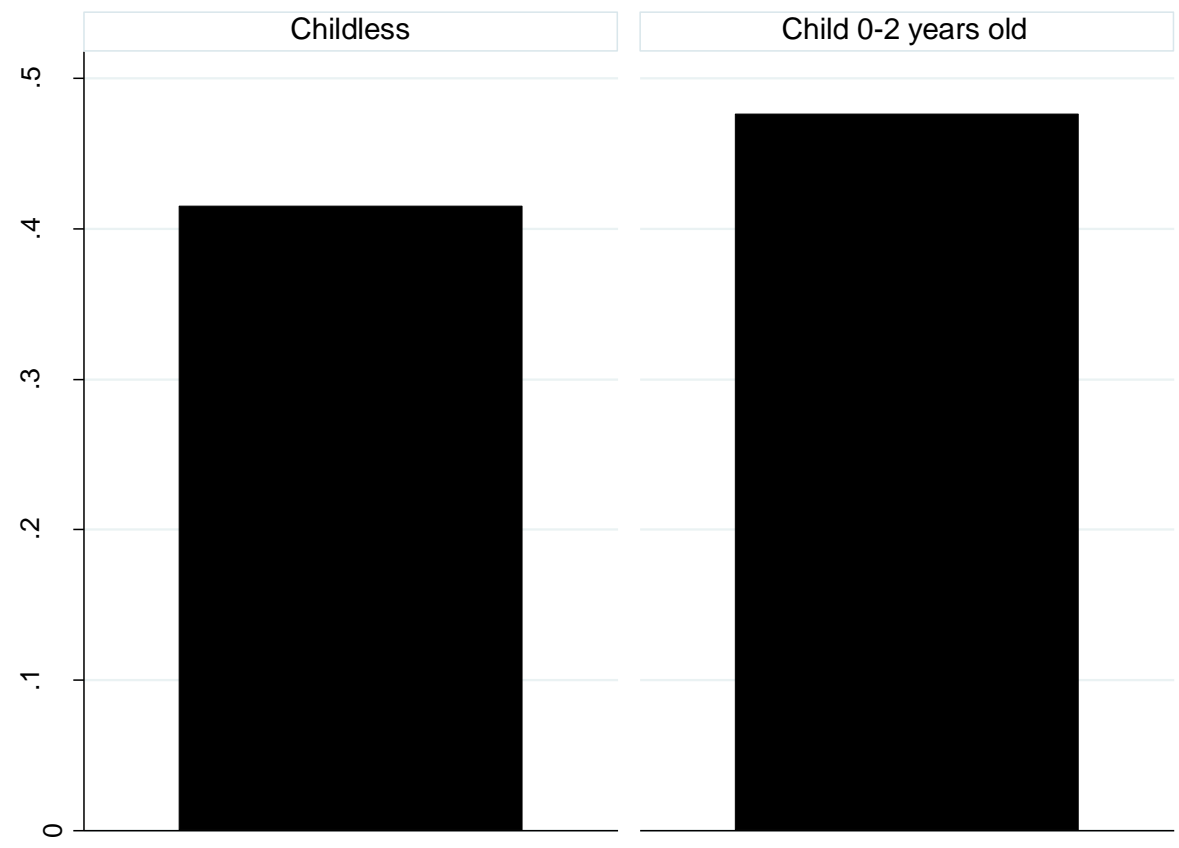

Figure 4. An example of a Directed Acyclic Graph (DAG)

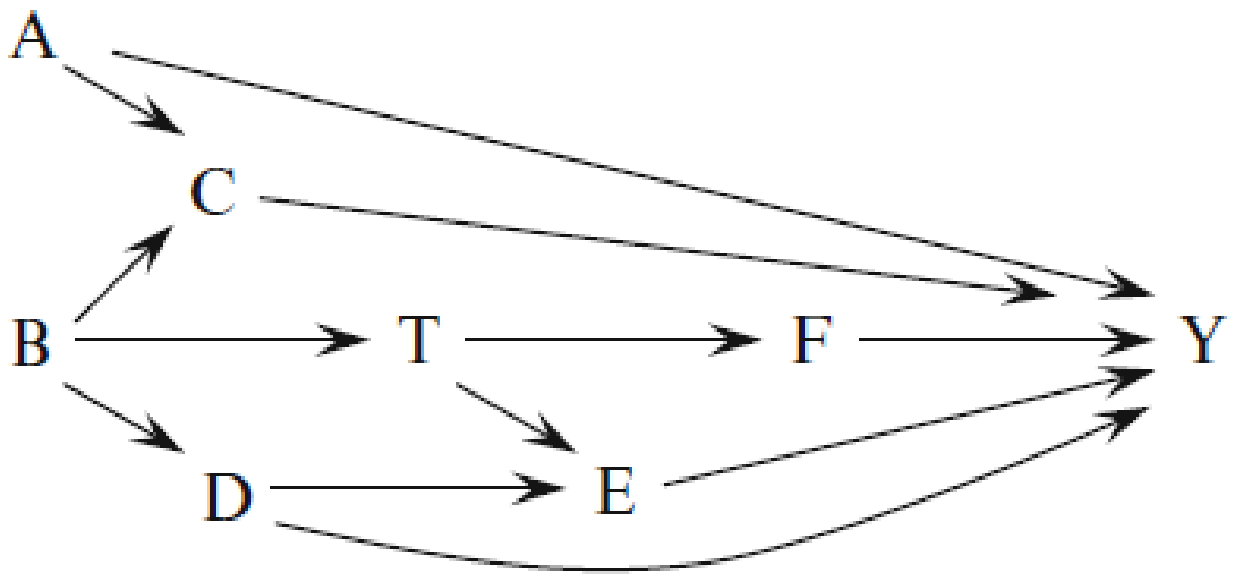


Figure 5. PC algorithm pseudo-code for the estimated DAG

Step 1:

Start with the complete undirected graph, $C^{\sim}$ with vertices $V=X_{l}, \ldots, X_{p}$. Then:

Step 2:

Set $l=-1$ and $\mathrm{C}=\mathrm{C}^{\sim}$

Step 3:

Increase $l$ by one. For all pairs of adjacent nodes:

- $\quad$ Check for conditional independence

- $\quad$ Remove edge $\left(X_{i}, X_{j}\right)$ if $X_{i} \perp \perp X_{j} \mid$ rest

Step 4:

Repeat step 2 until $l=m$ or until each node has fewer than $l-1$ neighbours

And let $m r$ each $\in \max l, m$ denote the stopping level of the algorithm and $q$ be the maximum number of neighbours

In plain words the above pseuso-code of the PC algorithm works on the following simple steps.

- $\quad$ For each $X$ and $Y$, see if $X \perp Y$; if so, remove their edge.

- $\quad$ For each $X$ and $Y$ which are still connected, and each third variable $Z 1$, see if $X \perp Y \mid Z$; if so, remove the edge between $\mathrm{X}$ and $\mathrm{Y}$.

- $\quad$ For each $X$ and $Y$ which are still connected, and each third and fourth variables

- $\quad \mathrm{Z} 1$ and $\mathrm{Z} 2$, see if $\mathrm{X} \perp \mathrm{Y} \mid \mathrm{Z} 1, \mathrm{Z} 2$; if so, remove their edge.

For each $\mathrm{X}$ and $\mathrm{Y}$ which are still connected, see if $\mathrm{X} \perp \mathrm{Y} \mid$ all the $\mathrm{p}-2$ other variables; if so, remove, their edge

Figure 6. Illustration of IV conditions

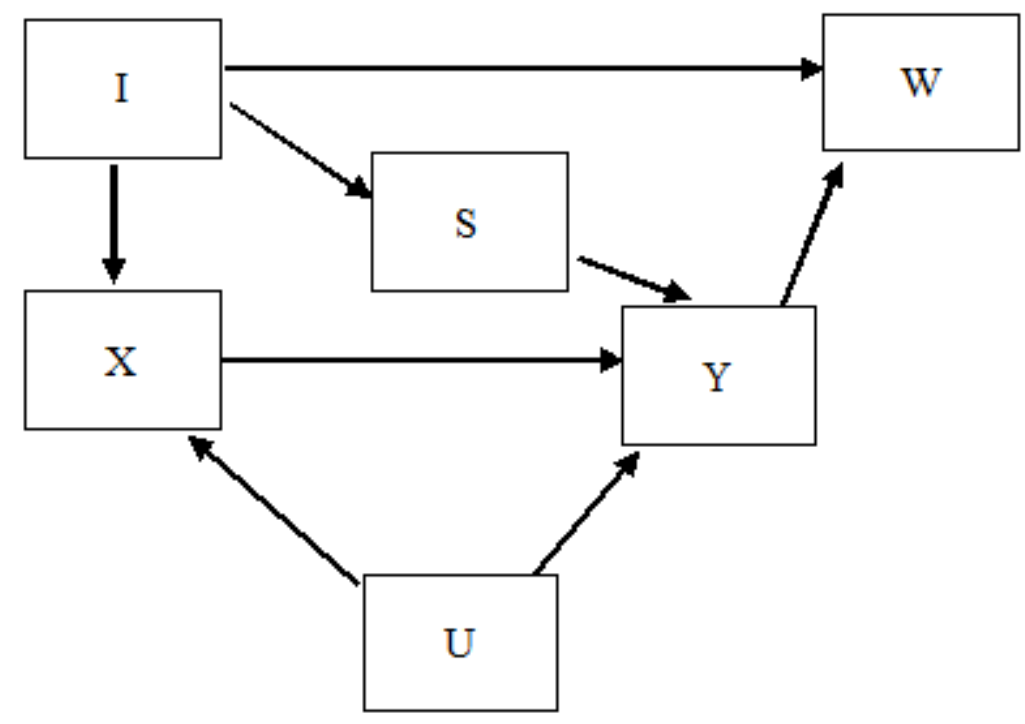


Figure 7. DAG for Teleworking

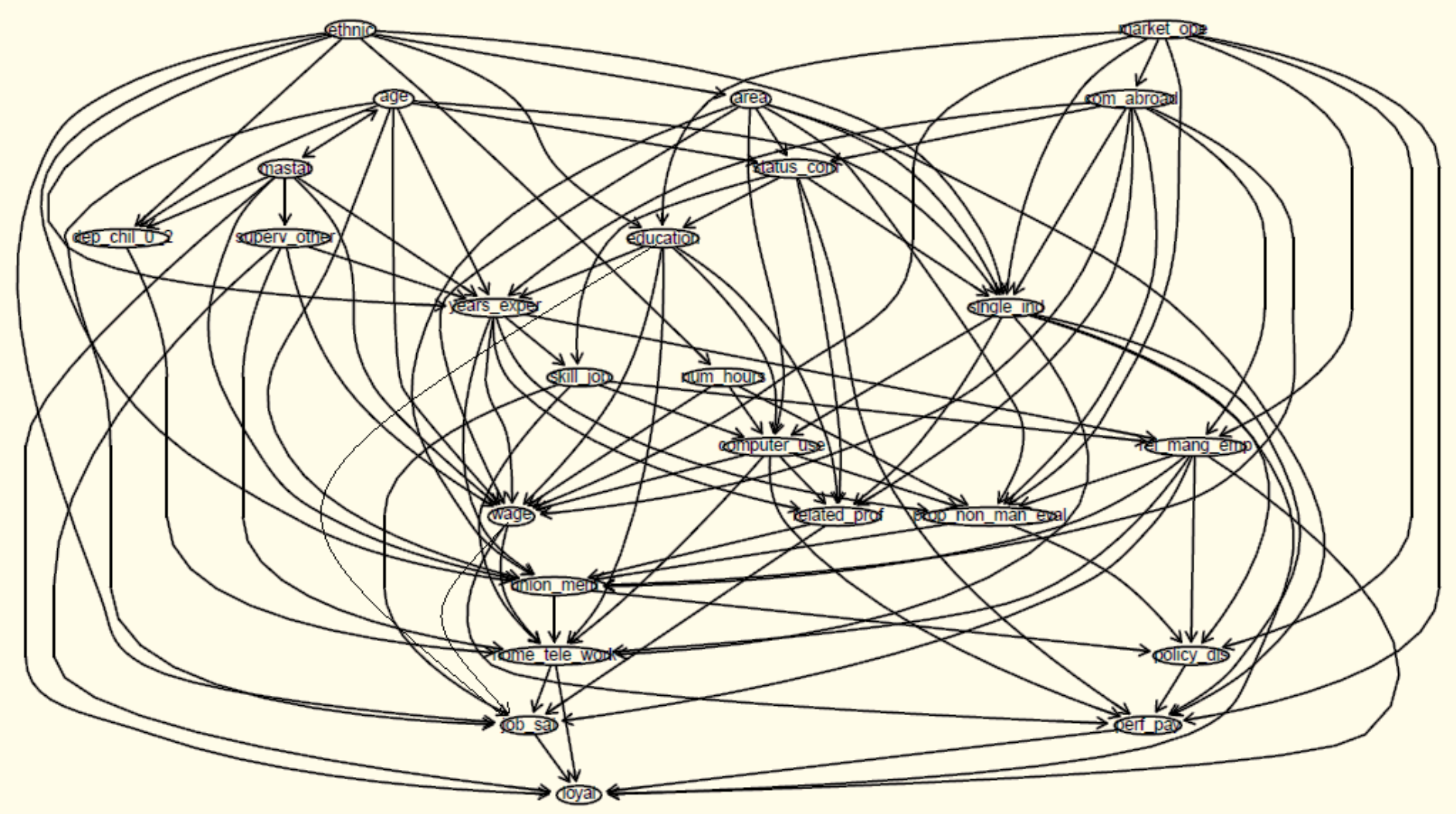


Table 1. Summary Statistics

\begin{tabular}{|c|c|c|c|c|c|}
\hline & Mean & $\begin{array}{c}\text { Standard } \\
\text { deviation }\end{array}$ & Minimum & Maximum & \\
\hline \multicolumn{7}{|c|}{ Panel A: Dependent Variables } \\
\hline Job Satisfaction & 3.8134 & 0.8939 & 1 & 5 & \\
\hline $\begin{array}{c}\text { Employee } \\
\text { Loyalty }\end{array}$ & 3.8423 & 0.9264 & 1 & 5 & \\
\hline \multicolumn{7}{|c|}{ Panel B: Employment Arrangements } & \\
\hline $\begin{array}{c}\text { Flexible Time } \\
\text { (Yes) }\end{array}$ & 39.08 & $\begin{array}{c}\text { Teleworking } \\
\text { (Yes) }\end{array}$ & 15.87 & & \\
\hline $\begin{array}{c}\text { Flexible Time } \\
\text { (No) }\end{array}$ & 60.92 & $\begin{array}{c}\text { Teleworking } \\
\text { (No) }\end{array}$ & 84.13 & & \\
\hline
\end{tabular}

Table 2. Correlation Matrix

\begin{tabular}{|c|c|c|c|}
\hline & Job satisfaction & Loyalty & Flexi time \\
\hline Loyalty & $0.4637 * * *$ & & \\
& $(0.0000)$ & & \\
\hline Flexi time & $0.1322 * * *$ & $0.1473 * * *$ & \\
& $(0.0000)$ & $(0.0000)$ & \\
\hline Teleworking & $0.1187 * * *$ & $0.1368 * * *$ & $0.2763 * * *$ \\
& $(0.0000)$ & $(0.0000)$ & $(0.0000)$ \\
\hline \multicolumn{4}{|c|}{ P-values in parentheses, $* * * \mathrm{p}<0.01$}
\end{tabular}


Table 3. Propensity Score Matching and OLS for Job Satisfaction

\begin{tabular}{|c|c|c|c|c|c|}
\hline VARIABLES & $(1)$ & $(2)$ & VARIABLES & $(1)$ & (2) \\
\hline Flexi Time & $\begin{array}{l}0.1564 * * * \\
(0.0221)\end{array}$ & & Performance related payments (Yes) & $\begin{array}{c}0.0331 * * \\
(0.0140)\end{array}$ & $\begin{array}{c}0.0535 * * \\
(0.0221)\end{array}$ \\
\hline Home-Teleworking & & $\begin{array}{c}0.1437 * * * \\
(0.0276)\end{array}$ & Skills matching job (much higher) & & \\
\hline Performance appraisal (Yes) & $\begin{array}{c}0.0226 \\
(0.0168)\end{array}$ & $\begin{array}{l}0.0420^{*} \\
(0.0220)\end{array}$ & Skills matching with job -bit higher & $\begin{array}{c}0.2210 \\
(0.1716)\end{array}$ & $\begin{array}{c}0.1465 \\
(0.1608)\end{array}$ \\
\hline Wage (reference $£ 141-£ 180$ per week & & & Skills matching with job-the same & $0.4142 * *$ & $0.4040 * * *$ \\
\hline Wage - £181-£220 per week & $\begin{array}{c}0.0372 \\
(0.0839)\end{array}$ & $\begin{array}{l}-0.0293 \\
(0.0771)\end{array}$ & Skills matching with job -bit lower & $\begin{array}{l}(0.1634) \\
0.3702 * *\end{array}$ & $\begin{array}{l}(0.1531) \\
0.3551 * *\end{array}$ \\
\hline Wage - £221-£260 per week & $\begin{array}{l}0.1575^{*} \\
(0.0816)\end{array}$ & $\begin{array}{c}0.0510 \\
(0.0763)\end{array}$ & Skills matching with job -much lower & $\begin{array}{c}(0.1637) \\
0.1597\end{array}$ & $\begin{array}{c}(0.1534) \\
0.1167\end{array}$ \\
\hline Wage - £261-£310 per week & $\begin{array}{l}0.1253^{*} \\
(0.0689)\end{array}$ & $\begin{array}{c}0.0444 \\
(0.0742)\end{array}$ & Quality of relations (very poor) & $(0.1645)$ & $(0.1544)$ \\
\hline Wage - £431-£540 per week & $\begin{array}{l}0.1349 * \\
(0.0782)\end{array}$ & $\begin{array}{c}0.0288 \\
(0.0745)\end{array}$ & Quality of relations-Poor & $0.3935^{* * *}$ & $0.4278 * * *$ \\
\hline Wage - $£ 681-£ 870$ per week & $\begin{array}{l}0.1491 * \\
(0.0803)\end{array}$ & $\begin{array}{c}0.1155 \\
(0.0764)\end{array}$ & Quality of relations-Neither good nor bad & $\begin{array}{c}(0.0801) \\
0.6272 * * * \\
(0.0756)\end{array}$ & $\begin{array}{c}(0.0801) \\
0.7114 * * * \\
(0.0754)\end{array}$ \\
\hline Wage - $£ 871$ or more per week & $\begin{array}{c}0.2329 * * \\
(0.0932)\end{array}$ & $\begin{array}{r}0.2021 * * \\
(0.0882)\end{array}$ & Quality of relations-Good & $0.9503 * * *$ & $1.0009 * * *$ \\
\hline $\begin{array}{l}\text { Gender (Female) } \\
\text { Age (reference category 16-17) }\end{array}$ & $\begin{array}{c}0.0989 * * * \\
(0.0278)\end{array}$ & $\begin{array}{c}0.0978 * * * \\
(0.0258)\end{array}$ & Quality of relations-Very Good & $\begin{array}{c}(0.0744) \\
1.2973 * * * \\
(0.0771)\end{array}$ & $\begin{array}{c}(0.0742) \\
1.3624 * * * \\
(0.0765)\end{array}$ \\
\hline Age (18-19) & $\begin{array}{l}-0.2096 * \\
(0.1188)\end{array}$ & $\begin{array}{l}-0.2621 * * \\
(0.1032)\end{array}$ & $\begin{array}{l}\text { Number of establishments (reference many) } \\
\text { Single }\end{array}$ & $\begin{array}{c}0.0194 \\
(0.0305)\end{array}$ & $\begin{array}{c}0.0253 \\
(0.0281)\end{array}$ \\
\hline Age (20-21) & $\begin{array}{l}-0.1433 \\
(0.1180)\end{array}$ & $\begin{array}{c}-0.2173 * * \\
(0.1007)\end{array}$ & Sole in UK-foreign & $\begin{array}{l}-0.0710 \\
(0.0618)\end{array}$ & $\begin{array}{l}-0.1276^{*} \\
(0.0640)\end{array}$ \\
\hline Age (22-29) & $\begin{array}{l}-0.0114 \\
(0.1044)\end{array}$ & $\begin{array}{l}-0.1221 \\
(0.0897)\end{array}$ & Supervise other employees (No) & $\begin{array}{c}-0.1157 * * * \\
(0.0258)\end{array}$ & $\begin{array}{c}-0.0932 * * * \\
(0.0243)\end{array}$ \\
\hline Age (30-39) & $\begin{array}{c}0.0508 \\
(0.1051)\end{array}$ & $\begin{array}{l}-0.0653 \\
(0.0905)\end{array}$ & $\begin{array}{l}\text { Market Area (reference-Local) } \\
\text { Market Area-Regional }\end{array}$ & $0.0816 * *$ & $0.0561 *$ \\
\hline Age (40-49) & $\begin{array}{c}0.0542 \\
(0.1069)\end{array}$ & $\begin{array}{l}-0.0606 \\
(0.0923)\end{array}$ & Market Area-National & $\begin{array}{c}(0.0368) \\
0.0398\end{array}$ & $\begin{array}{l}(0.0339) \\
-0.0105\end{array}$ \\
\hline Age (50-59) & $\begin{array}{c}0.1086 \\
(0.1083)\end{array}$ & $\begin{array}{l}-0.0036 \\
(0.0937)\end{array}$ & Market Area-International & $\begin{array}{l}(0.0311) \\
0.0653 *\end{array}$ & $\begin{array}{l}(0.0287) \\
0.0698 * *\end{array}$ \\
\hline Age (60-64) & $\begin{array}{l}0.3996 * * * \\
(0.1143)\end{array}$ & $\begin{array}{l}0.1965^{*} \\
(0.1010)\end{array}$ & & $(0.0386)$ & $(0.0351)$ \\
\hline Age (65 and above) & $\begin{array}{c}0.3262 * * \\
(0.1343)\end{array}$ & $\begin{array}{c}0.1597 \\
(0.1155)\end{array}$ & & & \\
\hline
\end{tabular}


Table 3 (cont.) Propensity Score Matching and OLS for Job Satisfaction

\begin{tabular}{|c|c|c|c|c|c|}
\hline VARIABLES & (1) & $(2)$ & VARIABLES & $(1)$ & $(2)$ \\
\hline Marital status (reference category single) & & & Body established by Royal Charter & $\begin{array}{c}0.0892 \\
(0.0724)\end{array}$ & $\begin{array}{c}0.1114 \\
(0.0685)\end{array}$ \\
\hline Marital status-Married or couple & $\begin{array}{c}0.0432 \\
(0.0819)\end{array}$ & $\begin{array}{l}0.1232 * \\
(0.0731)\end{array}$ & Trust/Charity & $\begin{array}{c}0.0456 \\
(0.0512)\end{array}$ & $\begin{array}{l}-0.0317 \\
(0.0490)\end{array}$ \\
\hline Marital status-Divorced & $\begin{array}{c}0.1395 * * * \\
(0.0451)\end{array}$ & $\begin{array}{l}0.0939 * * \\
(0.0432)\end{array}$ & Government-owned limited & $\begin{array}{l}-0.1238 \\
(0.0815)\end{array}$ & $\begin{array}{l}-0.1120 * \\
(0.0672)\end{array}$ \\
\hline Marital status-Widowed & $\begin{array}{c}0.0359 \\
(0.0299)\end{array}$ & $\begin{array}{c}0.0270 \\
(0.0277)\end{array}$ & $\begin{array}{l}\text { Member of Union Trade (reference Yes) } \\
\text { Member of union (No, but in the past) }\end{array}$ & $\begin{array}{c}0.0527 \\
(0.0331)\end{array}$ & $\begin{array}{c}0.0262 \\
(0.0231)\end{array}$ \\
\hline $\begin{array}{l}\text { Education level (reference primary } \\
\text { school) } \\
\text { Education level- GCSE D-E levels }\end{array}$ & -0.0211 & $-0.0417 *$ & Member of union (No never) & $\begin{array}{c}0.0835 * * \\
(0.0302)\end{array}$ & $\begin{array}{c}0.0934 * * * \\
(0.0217)\end{array}$ \\
\hline Education level- GCSE B-S levels & $\begin{array}{l}(0.0242) \\
-0.0456 \\
(0.0320)\end{array}$ & $\begin{array}{l}(0.0224) \\
-0.0314 \\
(0.0299)\end{array}$ & $\begin{array}{l}\text { Completion from abroad (A lot) } \\
\text { Completion from abroad-Little }\end{array}$ & -0.0214 & 0.0122 \\
\hline Education level- GCSE A-AS levels & $\begin{array}{l}-0.0452 \\
(0.0287)\end{array}$ & $\begin{array}{c}-0.0670 * * * \\
(0.0259)\end{array}$ & Completion from abroad-No & $\begin{array}{l}(0.0512) \\
-0.0338\end{array}$ & $\begin{array}{c}(0.0376) \\
0.0102\end{array}$ \\
\hline Education level-First degree & $\begin{array}{c}-0.0600 * * \\
(0.0305)\end{array}$ & $\begin{array}{c}-0.0762 * * * \\
(0.0280)\end{array}$ & Computer Use & $\begin{array}{l}(0.0458) \\
-0.00085\end{array}$ & $\begin{array}{r}(0.0299) \\
-0.00088\end{array}$ \\
\hline Education level-Higher degree & $\begin{array}{l}-0.0055 \\
(0.0510)\end{array}$ & $\begin{array}{c}0.0117 \\
(0.0459)\end{array}$ & Dependent children 0-2 years old & $\begin{array}{l}(0.0036) \\
-0.0105 \\
(0.0391)\end{array}$ & $\begin{array}{l}(0.0037) \\
0.0052 \\
(0.0448)\end{array}$ \\
\hline Type of Firm (reference Public) & & & Dependent children $>2$ years old & $\begin{array}{c}0.0025 \\
(0.0260)\end{array}$ & $\begin{array}{l}0.0016 \\
(0.0237)\end{array}$ \\
\hline Private limited company & $\begin{array}{c}0.0114 \\
(0.0281)\end{array}$ & $\begin{array}{l}-0.0376 \\
(0.0258)\end{array}$ & $\begin{array}{l}\text { No. Observations } \\
\text { R-Square }\end{array}$ & $\begin{array}{l}7,691 \\
0.2777\end{array}$ & $\begin{array}{l}7,503 \\
0.2659\end{array}$ \\
\hline Company limited by guarantee & $\begin{array}{c}0.0748 \\
(0.0633)\end{array}$ & $\begin{array}{c}0.0068 \\
(0.0561)\end{array}$ & & & \\
\hline Partnership & $\begin{array}{c}0.0475 \\
(0.0515)\end{array}$ & $\begin{array}{c}0.0107 \\
(0.0486)\end{array}$ & & & \\
\hline
\end{tabular}

The estimates for flexi-time and teleworking are respectively reported in columns (1) and (2). Robust standard errors in parentheses, $* * * \mathrm{p}<0.01, * * \mathrm{p}<0.05, * \mathrm{p}<0.1$ 
Table 4. Propensity Score Matching and OLS for Employee Loyalty

Variables (1) (2)

\begin{tabular}{ccc}
\hline Flexible time & $\begin{array}{c}0.1428^{* * * *} \\
(0.0111)\end{array}$ \\
Teleworking & & $\begin{array}{c}0.1158^{* * *} \\
\end{array}$ \\
Observations & 7,140 & 7,368 \\
& & \\
R-squared & 0.3232 & 0.3087 \\
\hline \multicolumn{2}{c}{ Robust standard errors in parentheses, ${ }^{* * *} \mathrm{p}<0.01$}
\end{tabular}

Table 5. Propensity Score Matching and Ordered Probit

\begin{tabular}{ccccc}
\hline Variables & $\begin{array}{c}(\mathbf{1}) \\
\text { DV: Job } \\
\text { Satisfaction }\end{array}$ & $\begin{array}{c}\mathbf{( 2 )} \\
\text { DV: Job } \\
\text { Satisfaction }\end{array}$ & $\begin{array}{c}\mathbf{( 3 )} \\
\text { DV: Employee } \\
\text { Loyalty }\end{array}$ & $\begin{array}{c}(\mathbf{4}) \\
\text { DV: Employee } \\
\text { Loyalty }\end{array}$ \\
\hline Flexible time & $0.2085^{* * *}$ & & $0.1913^{* * *}$ & \\
& $(0.0318)$ & & $(0.0162)$ & \\
Teleworking & & $0.2008^{* * *}$ & & $0.1830^{* * * *}$ \\
& & $(0.0406)$ & & $(0.0403)$ \\
Observations & 7,291 & 7,503 & 7,140 & 7,368 \\
& & & & 0.1439 \\
Pseudo R-Square & 0.1323 & 0.1243 & 0.1493 & \\
Wald chi square & $4,578.65$ & $4,725.33$ & $4,326.97$ & 4561.24 \\
& {$[0.000]$} & {$[0.000]$} & {$[0.000]$} & {$[0.000]$} \\
\hline
\end{tabular}

Robust standard errors in parentheses, P-values within brackets $* * * \mathrm{p}<0.01$

Columns (1)-(2) are estimated respectively for flexi-time and teleworking and the dependent variable is the job satisfaction. Similarly, in columns (3)-(4) the respective estimates using employee loyalty as the dependent variable are presented. 
Table 6. BN and DAG Estimates for Job Satisfaction, Employee Loyalty and Employee Arrangements

\begin{tabular}{|c|c|c|c|c|}
\hline VARIABLES & $\begin{array}{l}\text { (1) } \\
\text { OLS }\end{array}$ & $\begin{array}{l}(2) \\
\text { OLS }\end{array}$ & $\begin{array}{l}\text { (3) } \\
\text { OP }\end{array}$ & $\begin{array}{l}\text { (4) } \\
\text { OP }\end{array}$ \\
\hline \multicolumn{5}{|l|}{ Panel A: Dependent Variable Job Satisfaction } \\
\hline Flexible time & $\begin{array}{c}0.1643 * * * \\
(0.0193)\end{array}$ & & $\begin{array}{l}0.2939 * * * \\
(0.0458)\end{array}$ & \\
\hline Teleworking & & $\begin{array}{c}0.1671 * * * \\
(0.0335)\end{array}$ & & $\begin{array}{c}0.2725 * * * \\
(0.0718)\end{array}$ \\
\hline Observations & 7,291 & 7,503 & 7,291 & 7,503 \\
\hline \multicolumn{5}{|l|}{ Panel B: Dependent Variable Employee Loyalty } \\
\hline Flexible time & $\begin{array}{c}0.1523 * * * \\
(0.0182)\end{array}$ & & $\begin{array}{l}0.2744 * * * \\
(0.0468)\end{array}$ & \\
\hline Teleworking & & $\begin{array}{c}0.1503 * * * \\
(0.0285)\end{array}$ & & $\begin{array}{c}0.2632 * * * \\
(0.0718)\end{array}$ \\
\hline \multicolumn{5}{|l|}{$\begin{array}{c}\text { Job satisfaction (reference category-very } \\
\text { dissatisfied) }\end{array}$} \\
\hline Job satisfaction-dissatisfied & $\begin{array}{c}0.4224 * * * \\
(0.0594)\end{array}$ & $\begin{array}{c}0.3727 * * * \\
(0.0629)\end{array}$ & $\begin{array}{c}0.8140 * * * \\
(0.1478)\end{array}$ & $\begin{array}{c}0.7089 * * * \\
(0.1556)\end{array}$ \\
\hline Job satisfaction-neither dissatisfied nor satisfied & $\begin{array}{c}0.6246 * * * \\
(0.0545)\end{array}$ & $\begin{array}{c}0.5652 * * * \\
(0.0580)\end{array}$ & $\begin{array}{l}1.1978 * * * \\
(0.1370)\end{array}$ & $\begin{array}{c}1.0815 * * * \\
(0.1447)\end{array}$ \\
\hline Job satisfaction- satisfied & $\begin{array}{c}1.0116 * * * \\
(0.0529)\end{array}$ & $\begin{array}{c}0.9881 * * * \\
(0.0565)\end{array}$ & $\begin{array}{l}2.1370 * * * \\
(0.1352)\end{array}$ & $\begin{array}{c}2.0731 * * * \\
(0.1432)\end{array}$ \\
\hline Job satisfaction- very satisfied & $\begin{array}{c}1.3999 * * * \\
(0.0571)\end{array}$ & $\begin{array}{c}1.3654 * * \\
(0.0624)\end{array}$ & $\begin{array}{l}3.4082 * * * \\
(0.1483)\end{array}$ & $\begin{array}{c}3.2731 * * * \\
(0.1562)\end{array}$ \\
\hline Observations & 7,140 & 7,368 & 7,140 & 7,368 \\
\hline
\end{tabular}

Robust standard errors in parentheses, $* * * \mathrm{p}<0.01, * * \mathrm{p}<0.05, * \mathrm{p}<0.01$

Columns (1)-(2) are estimated with OLS respectively for flexi-time and teleworking. Similarly, in columns (3)-(4) the respective estimates using ordered Probit are reported. In Panel A the dependent variable is job satisfaction and in panel B the dependent variable is employee loyalty. 
Table 7. 2SLS and IV-DAG Estimates for Job Satisfaction and Employee Loyalty

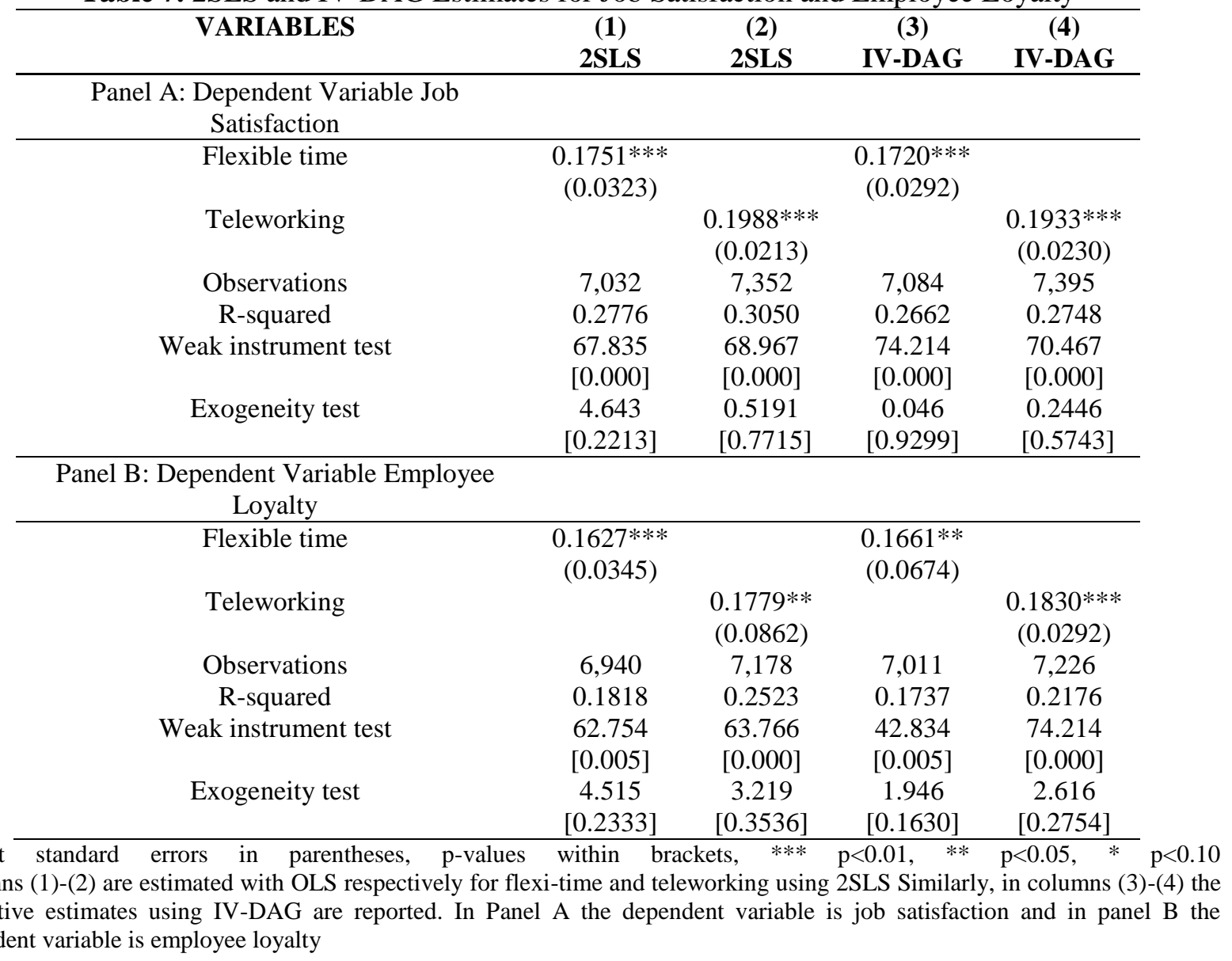

